\title{
The SAM, Not the Electrodes, Dominates Charge Transport in Metal-Monolayer//Ga203/Gallium- Indium Eutectic Junctions
}

\section{Citation}

Reus, William F., Martin M. Thuo, Nathan D. Shapiro, Christian A. Nijhuis, and George M. Whitesides. 2012. The SAM, Not the Electrodes, Dominates Charge Transport in MetalMonolayer//Ga203/Gallium-Indium Eutectic Junctions. ACS Nano 6, no. 6: 4806-4822.

\section{Published Version}

doi:10.1021/nn205089u

\section{Permanent link}

http://nrs.harvard.edu/urn-3:HUL.InstRepos:11956910

\section{Terms of Use}

This article was downloaded from Harvard University's DASH repository, and is made available under the terms and conditions applicable to Open Access Policy Articles, as set forth at http:// nrs.harvard.edu/urn-3:HUL.InstRepos:dash.current.terms-of-use\#OAP

\section{Share Your Story}

The Harvard community has made this article openly available.

Please share how this access benefits you. Submit a story.

\section{Accessibility}




\section{The SAM, Not the Electrodes, Dominates Charge Transport in}

\section{$\mathrm{Ag}^{\mathrm{TS}}$-SAM $/ / \mathrm{Ga}_{2} \mathrm{O}_{3} / \mathbf{E G a I n}$ Junctions}

William F. Reus, ${ }^{1}$ Martin M. Thuo, ${ }^{1}$ Nathan D. Shapiro ${ }^{1}$, Christian A. Nijhuis, ${ }^{1,2}$ and George M. Whitesides ${ }^{1,3^{*}}$

${ }^{1}$ Department of Chemistry and Chemical Biology, Harvard University, 12 Oxford St, Cambridge, MA 02138, USA.

${ }^{2}$ Department of Chemistry, National University of Singapore, 3 Science Drive 3, Singapore 117543.

${ }^{3}$ Kavli Institute for Bionano Science \& Technology, Harvard University, School of Engineering and Applied Sciences, Pierce Hall, 29 Oxford St., Cambridge, MA 02138

*corresponding author:

Tel.: 6174589430

Fax.: 6174589857

e-mail: gwhitesides@gmwgroup.harvard.edu 


\begin{abstract}
The liquid-metal eutectic of gallium and indium (EGaIn) is a useful electrode for making soft electrical contacts to self-assembled monolayers (SAMs). This electrode has, however, one feature whose effect on charge transport has been incompletely understood: a thin (approximately $0.7 \mathrm{~nm}$ ) film — consisting primarily of $\mathrm{Ga}_{2} \mathrm{O}_{3}$ - that covers its surface when in contact with air. SAMs that rectify current have been measured using this electrode in $\mathrm{Ag}^{\mathrm{TS}}$-SAM// $\mathrm{Ga}_{2} \mathrm{O}_{3} / \mathrm{EGaIn}$ junctions. This paper organizes evidence, both published and unpublished, showing that the molecular structure of the SAM (specifically, the presence of an accessible molecular orbital asymmetrically located within the SAM), not the difference between the electrodes or the characteristics of the $\mathrm{Ga}_{2} \mathrm{O}_{3}$ film, causes the observed rectification. By examining and ruling out potential mechanisms of rectification that rely either on the $\mathrm{Ga}_{2} \mathrm{O}_{3}$ film, or on the asymmetry of the electrodes, this paper demonstrates that the structure of the SAM dominates charge transport through $\mathrm{Ag}^{\mathrm{TS}}-\mathrm{SAM} / / \mathrm{Ga}_{2} \mathrm{O}_{3} / \mathrm{EGaIn}$ junctions, and that the electrical characteristics of the $\mathrm{Ga}_{2} \mathrm{O}_{3}$ film have a negligible effect on these measurements.
\end{abstract}




\section{Introduction}

In the decades since Aviram and Ratner first proposed a design for a molecular diode, ${ }^{1}$ many experiments have been claimed to demonstrate rectification of current in systems involving molecular components. ${ }^{2,3,4,5,6,7,8,9,10,11}$ Many of these reports involved experimentally difficult systems, and it has not always been clear that the rectification is either statistically significant, or due to the molecules in the junctions (rather than, say, processes involving redox reactions, or metal filaments). These ambiguities have been sufficiently disquieting that there has developed a substantial, and understandable, skepticism about interpretation of all reports of molecular rectification involving asymmetric or oxidizable electrodes. ${ }^{12}$

Since we report measurements of charge transport and rectification using a system with both asymmetric and oxidizable electrodes, we are interested in demonstrating that our system yields reliable information about SAMs. Our shorthand for the structures of these junctions is $\mathrm{Ag}^{\mathrm{TS}}$-SAM//Ga $\mathrm{O}_{3} / \mathrm{EGaIn}: \mathrm{Ag}^{\mathrm{TS}}$ is so-called "template-stripped" (e.g., smooth) silver (the fabrication of which we $\mathrm{e}^{13,14}$ and others ${ }^{15,16}$ have described elsewhere), SAMs are those generated under carefully specified controlled conditions (and especially using freshly and carefully purified thiols), “//" indicates a van der Waals interface, and $\mathrm{Ga}_{2} \mathrm{O}_{3} / \mathrm{EGaIn}$ denotes the eutectic alloy of gallium and indium with its $\sim 0.7 \mathrm{~nm}$-thick, self-passivating, surface layer of metal oxide ${ }^{17}$ (with composition approximately $\mathrm{Ga}_{2} \mathrm{O}_{3}$, but with small amounts of indium oxide and non-stoichiometric gallium oxide). ${ }^{18}$ This gallium oxide film is analogous to the oxide films that form on the surface of $\mathrm{Al}, \mathrm{Ti}$, and $\mathrm{Si}$, but with — of course - its own physical and chemical properties. The characteristics of all the components of this system are relatively well documented (although sometimes 
still incompletely understood), with the exception of the " $\mathrm{Ga}_{2} \mathrm{O}_{3}$ " film (which we write henceforth simply as $\mathrm{Ga}_{2} \mathrm{O}_{3}$, but understanding that its surface - if prepared in ambient conditions - is contaminated with adsorbed organic materials, and contains small amounts of indium and other oxidation states of gallium).

Since all experimental systems have the potential for artifacts, we suggest thatrather than including some systems and/or excluding others due to the potential for redox activity — it is more appropriate that every experimental system, and every claim of molecular rectification, be appropriately qualified. That is, the experimental results must be reproducible and amenable to statistical analysis, and be backed by controls that rule out, or bound, all plausible non-molecular mechanisms. The goal of this paper is to focus on the major sources of uncertainty in our junctions - the influence of the $\mathrm{Ga}_{2} \mathrm{O}_{3}$ film and the differences between the Fermi levels of the two metal electrodes $(\mathrm{Ag} \approx-4.5 \mathrm{eV}$ and EGaIn $\approx-4.2 \mathrm{eV})^{19}$-and to assemble all the currently available evidence (published and unpublished) that we interpret to indicate that they do not significantly affect our results.

The presence of this $\mathrm{Ga}_{2} \mathrm{O}_{3}$ film on the surface of "conical tip" electrodes is essential for their function, but the film itself raises three concerns: i) Electrical Conductivity. The electrical conductivity of pure $\mathrm{Ga}_{2} \mathrm{O}_{3}$ depends on its method of preparation, and in principle, it might contribute substantial resistance to the junction. In fact, experimental measurements suggest that the resistance of the oxide film $\left(\sim 10^{5}-10^{6} \Omega\right)$ is approximately three orders of magnitude smaller than the resistance of the most

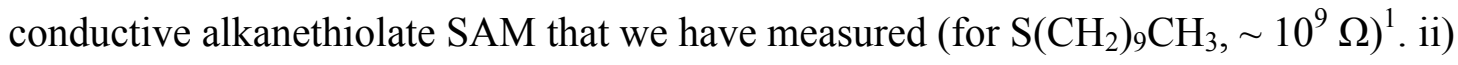
Adsorbed Organic Contaminants. Experiments with X-ray Photoelectron Spectroscopy

${ }^{1}$ on $\sim 1 \mathrm{~cm}$ of the respective material 
and Time of Flight Secondary Ion Mass Spectrometry (ToF-SIMS) indicate that the surface of the $\mathrm{Ga}_{2} \mathrm{O}_{3}$ film on EGaIn (as with most other surfaces exposed to the ambient environment and even some prepared in controlled atmospheres) supports a layer of adsorbed organic material that probably comprises volatile organic compounds, such as hydrocarbons and carboxylic acids. ${ }^{18}$ This layer is probably a discontinuous network of islands and probably forms slowly on the timescale of the lifetime of a junction $(>10$ $\min )$, rather than a continuous sheet, ${ }^{20}$ and while it is the least understood component of our system, it has not prevented us from observing even molecular effects that are quite subtle (e.g., odd vs. even alternation in n-alkanethiolates). ${ }^{21}$ iii). Potential for Redox Behavior, or for Other Processes That Might Cause Electrical Artifacts. The reduction potential of $\mathrm{Ga}(\mathrm{III})$ and $\mathrm{Ga}(\mathrm{I})$ in the environment of the surface film is not known. Table S1 (in the Supporting Information) gives the reduction potentials of these species in aqueous solution, along with reduction potentials for other relevant species of $\mathrm{Ga}, \mathrm{In}, \mathrm{Sn}$, Al, Ti, and Ag. Gallium (III) is, thus, probably easier to reduce than Al(III), but more difficult to reduce than $\mathrm{Ag}(\mathrm{I})$.

Objective. The objective of this paper is to examine $\mathrm{Ag}^{\mathrm{TS}}-\mathrm{SAM} / / \mathrm{Ga}_{2} \mathrm{O}_{3} / \mathrm{EGaIn}$ junction's behavior, using rectification as a probe, in order to establish whether the electrical characteristics of these systems - and especially rectification in a specific system $\left(\mathrm{Ag}^{\mathrm{TS}}-\mathrm{S}\left(\mathrm{CH}_{2}\right)_{11} \mathrm{Fc} / / \mathrm{Ga}_{2} \mathrm{O}_{3} / \mathrm{EGaIn}\right)$ — are determined by the organic/organometallic molecules in the SAMs, or by other components and/or characteristics of the systems (e.g., the difference in work function between the electrode, the interfaces in the junction, or the $\mathrm{Ga}_{2} \mathrm{O}_{3}$ film). We particularly wished to understand if this gallium oxide film 
strongly influences charge transport through these junctions, especially in ways that could be mistaken for molecular rectification.

Rectification as a Model System. We have selected rectification - rather than the more commonly studied measurement of current density $\left(\mathrm{J}, \mathrm{A} / \mathrm{cm}^{2}\right)$ as a function of voltage $(V$, amps $)$ - as the electrical characteristic to use as a probe in these junctions, since it is particularly insensitive to some types of artifacts. Many of the experimental results we describe were obtained using a conical tip electrode. ${ }^{21}$ This electrode has the advantage of convenience, but the disadvantage that several of its characteristics-and especially the contact area-are not completely defined (we discuss this issue in a following section). Rectification eliminates or reduces many artifacts, such as those from uncertainty in contact area: because the same junction provides $J$ at positive and negative bias, many characteristics of the junction (contact area, distribution of defects, density and distribution of organic contaminants, thickness and topography of the $\mathrm{Ga}_{2} \mathrm{O}_{3}$ film) are constants for any specific junction. All of these characteristics ultimately must be studied independently by comparing rectification in different junctions, but the ability to compare $J(+\mathrm{V})$ and $J(-\mathrm{V})$ in exactly the same junction is an invaluable asset in a basic scientific inquiry into the relative contributions of the SAM (or the molecules in it - not necessarily exactly the same thing) and the $\mathrm{Ga}_{2} \mathrm{O}_{3}$ layer.

In addition to providing a system that is self-referencing, the study of rectification lends itself to testing clearly defined hypotheses. For example, we have falsified (and continue to show evidence against) the hypothesis that molecular rectification requires a D- $\sigma$-A structure. In a previous publication, ${ }^{22}$ we have measured rectification in a series of compounds incorporating ferrocene $(\mathrm{Fc})$ moieties, placed in different positions 
between the $\mathrm{Ag}^{\mathrm{TS}}$ and $\mathrm{Ga}_{2} \mathrm{O}_{3} / E$ EaIn electrodes, and were able to test three different theoretical predictions about the relationship of the rectification ratio to the structure of the rectifier (we summarize these results in the "Background" section). In a field that has often struggled to correlate theory with experiment, molecular rectification has been a rare example of success in this regard.

The Structure of this Paper. Information relevant to various electrical characteristics of the $\mathrm{Ag}^{\mathrm{TS}}-\mathrm{SAM} / / \mathrm{Ga}_{2} \mathrm{O}_{3} / \mathrm{EGaIn}$ junction, and especially the $\mathrm{Ga}_{2} \mathrm{O}_{3}$ layer, is distributed in a number of papers already published, including several describing rectification in SAMs containing Fc groups. ${ }^{21,22,23,24}$ Because this information is scattered, and because its discussion has not always focused on understanding the $\mathrm{Ga}_{2} \mathrm{O}_{3}$ layer, it is currently understandably difficult for someone currently not active in the field to build a coherent picture of this critical component of the $\mathrm{Ag}^{\mathrm{TS}}-\mathrm{SAM} / \mathrm{Ga}_{2} \mathrm{O}_{3} / \mathrm{EGaIn}$ junction. In this paper, we first review (in the "Background" section) our published work on rectification, emphasizing SAMs containing Fc groups. We then describe (in the "Results" section) new experimental studies of rectification in SAMs containing polar and redox-active terminal groups other than Fc. Finally, we discuss (in the "Discussion" section) these data, and relevant data from the literature, in terms of two concerns: the electrical characteristics of the $\mathrm{Ga}_{2} \mathrm{O}_{3}$ layer, and the mechanism of rectification. The "Discussion" section is divided into seven subsections, with the first subsection supporting the molecular origin of rectification, and with each following subsection addressing a hypothesis for how the $\mathrm{Ga}_{2} \mathrm{O}_{3}$ layer or the electrodes might exert unwanted influence over charge transport. Briefly, the hypotheses are: i) The difference between the Fermi levels of the electrodes causes rectification. ii) Dipoles embedded in the SAM, the $\mathrm{Ga}_{2} \mathrm{O}_{3}$ 
layer, or the $\mathrm{Ag}-\mathrm{S}$ interface cause rectification. iii) Redox processes in the $\mathrm{Ga}_{2} \mathrm{O}_{3}$ layer significantly affect charge transport, iv) redox processes involving both the $\mathrm{Ga}_{2} \mathrm{O}_{3}$ layer and the SAM significantly affect charge transport. v) The $\mathrm{Ga}_{2} \mathrm{O}_{3}$ layer forms a Schottky barrier (with either the bulk EGaIn or the SAM) and causes rectification. vi) Mobile or variable dopants in the $\mathrm{Ga}_{2} \mathrm{O}_{3}$ layer cause memristor ${ }^{25}$-like behavior. Within each subsection, we summarize the hypothesis in question, give the relevant evidence that confirm or counter it, and draw a conclusion from that evidence. This format helps to organize the discussion.

To anticipate our conclusions, we find that $\mathrm{i}$ ) artifacts due to the $\mathrm{Ga}_{2} \mathrm{O}_{3}$ layer do not cause rectification; instead, rectification is due to the redox active molecules incorporated in the SAMs. ii) The mechanism of rectification requires the asymmetric placement of an accessible molecular orbital (that due to the Fc group) between the electrodes, such that the orbital can undergo redox reactions at one bias, but not the opposite bias. iii) The other characteristics of the junctions (the topography of the interfaces, surface contamination, the contact area, the composition of the $\mathrm{Ga}_{2} \mathrm{O}_{3}$ layer) do contribute to $J(\mathrm{~V})$ : rectification within a single junction is, however, more reproducible than rectification in different junctions, which is more reproducible than $J(\mathrm{~V})$ in different junctions. All are, however, usefully diagnostic of the contribution of the structure of the SAM to the rates of charge transport across the junction. iv) Rectification does not require an embedded electrical dipole, but rather (in our system) correlates with an accessible molecular orbital or orbitals.

Defining the Rectification Ratio. Before discussing possible mechanisms for rectification, we wish to give a cumbersome but unambiguous definition of the 
rectification ratio. For most diodes, researchers have chosen a particular voltage, $V$, and measured the current (or current density, $J$ ) at $V$ and $-V$. Of the two applied voltages, the one that gives the greater $|J|$ is considered forward bias $\left(V_{f w d}\right)$, while the one that gives the lesser $|J|$ is the reverse bias $\left(V_{\text {rev }}=-V_{f w d}\right)$. The rectification ratio, then, is the magnitude of the ratio of current density at forward bias to that at reverse bias. We (and others) have used this definition (eq. 1) in all of our reports of rectification thus far.

$$
\text { rectification ratio } \equiv\left|\frac{J\left(V_{\text {fwd }}\right)}{J\left(V_{\text {rev }}\right)}\right|
$$

This definition functions adequately when i) one is reporting single measurements, rather than analyzing a statistical ensemble of measurements, and ii) all that is important is the magnitude of rectification, and not the direction of rectification - that is, the polarity of the electrodes, with respect to the structure of the rectifying junction, at forward bias. For example, the statement that "SAMs of $\mathrm{S}\left(\mathrm{CH}_{2}\right)_{11} \mathrm{Fc}$ show rectification ratios of 100, while SAMs of $\mathrm{S}\left(\mathrm{CH}_{2}\right)_{10} \mathrm{CH}_{3}$ yield rectification rations around 1.5", informs the reader that the former is a much better rectifier than the latter, but it does not reveal that forward bias for the $\mathrm{S}\left(\mathrm{CH}_{2}\right)_{11} \mathrm{Fc}$ occurs when the EGaIn electrode is biased negatively, while forward bias for $\mathrm{S}\left(\mathrm{CH}_{2}\right)_{10} \mathrm{CH}_{3}$ occurs when EGaIn is biased positively. Knowing the direction of rectification is crucial to characterizing the mechanism of rectification.

For this reason, we began by measuring a statistical ensemble of rectification ratios, where each ratio was defined without regard to forward or reverse bias. This definition of $r$ (eq. 2), by itself, is not very informative: all values of $r$ are negative, and most values

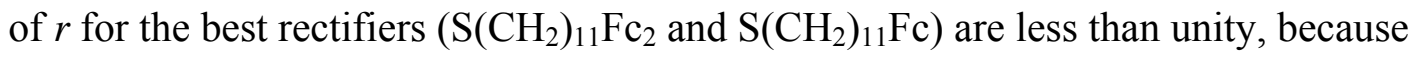
forward bias is negative for these rectifiers. 


$$
r \equiv \frac{J(+V)}{J(-V)}
$$

This definition of $r$ is, however, consistent across all rectifiers, and statistical analysis of distributions of $\log |r|$ is useful ( $r$ is approximately $\log$-normally distributed, so $\log |r|$ is approximately normally distributed). ${ }^{22,23}$ The average of $\log |r|,<\log |r|>$, conveys both the magnitude and direction of rectification: $<\log |r|>$ takes on the sign of $V_{f w d}$. Furthermore, the standard deviation $(\sigma)$ of $\log |r|$ accurately quantifies the error in the measurement of the rectification ratio.

The field of molecular electronics is, however, accustomed to evaluating rectification ratios using a linear, rather than a logarithmic, scale. In order to report a value, on a linear scale, that conveys both the magnitude and the direction of rectification, we use the definition of rectification ratio, $R$, given by eq. 3 .

$$
R \equiv \operatorname{sign}(\langle\log |r|\rangle) 10^{|\langle\log |r|\rangle|}
$$

This definition of $R$ conveys the direction of rectification by taking the sign of $V_{f w d}$, while also having the same magnitude as the traditional definition of rectification (eq. 1), without depending on shifting definitions of $V_{f w d}$ and $V_{\text {rev }}$. The downside of using $R$ is that there is no accurate and convenient way to report error: because $R$ is not normally distributed, it cannot be reported as value \pm error, whereas this format is appropriate for $<\log |r|>$, since it is approximately normally distributed. In our opinion, both $<\log |r|>( \pm$ $\sigma)$ and $R$ are informative - the former for giving a sense of the error or statistical uncertainty in the value, and the latter for communicating the magnitude of the value. As such, we have reported both quantities in Table 1, and will reference both in this paper. 
Rectification in Organic Monolayers. Aviram and Ratner ${ }^{1}$ first hypothesized a structure for a molecular diode that would lead to rectification. This hypothesis involved an electron donor-bridge-electron acceptor (D-bridge-A) structure, where a $\sigma$-bonded system would disrupt the conjugation between $\mathrm{D}$ and $\mathrm{A}$. This structure is analogous to the p-n structure of diodes involving semiconductors. In this proposal, due to the relative energies of the molecular orbitals of the D and A moieties, electrons would theoretically be able to flow from $\mathrm{A}$ to $\mathrm{D}$ at a lower applied bias than would be required to flow in the opposite direction (from D to A); this difference would result in rectification.

After the proposal of Aviram and Ratner, Wrighton et al. fabricated a diode ${ }^{26}$ based on a junction between two polymers (a ferrocene-based electron acceptor and a bipyridinium-based electron donor) grown on Au microelectrodes in an electrochemical cell. While this diode required electron transfer from a donor to an acceptor, the mechanism of charge transport did not involve tunneling (the length of the active portion of the device was on the order of $1 \mu \mathrm{m}$ ), but rather a pair of redox reactions in a wet electrochemical environment. The structure of the molecular rectifier proposed by Aviram and Ratner, by contrast, depended on a tunneling barrier with a complicated energetic topography. The polymeric diodes of Wrighton et al. are, therefore, only tangentially relevant to the questions of molecular rectification raised by Aviram and Ratner, and discussed in this paper.

Most efforts in the area of molecular rectification have focused on demonstrating rectification in junctions containing Langmuir-Blodgett (LB) films, or self-assembled monolayers (SAMs), of molecules with the D-bridge-A structure (with different definitions of "bridge", for reasons of synthetic accessibility). For example, in 1990, 
Ashwell and Sambles et al. ${ }^{27}$ reported rectification from a compound (hexadecylquinolinium tricyanoquinodimethanide, $\mathrm{C}_{16} \mathrm{H}_{33} \mathrm{Q}-3 \mathrm{CNQ}$ ) comprising a zwitterionic $\mathrm{D}^{+}$-bridge- $\mathrm{A}^{-}$head-group attached to a 16-carbon alkyl chain (the purpose of the alkyl chain was to cause the molecules to orient in the same direction within the film; whether it did so is unknown). When sandwiched between Pt and Mg electrodes, this molecule showed asymmetric current vs. voltage, $I(\mathrm{~V})$, characteristics. No control experiments were, however, reported, and due to the asymmetry of the electrodes and the strong dipole intrinsic to the molecule, the authors could not conclude that the rectification had a molecular origin. (Incidentally, in this work, the authors used EGaIn as a solder to connect the $\mathrm{Mg}$ electrodes in their junctions to an external circuit; the EGaIn was not used to contact the molecular monolayer.)

Later, in 1999, Metzger et al. ${ }^{28}$ formed LB films of the same compound on $\mathrm{Al}$ (also $\mathrm{Au}$ ) and evaporated $\mathrm{Al}$ (or $\mathrm{Au}$ ) top-contacts contacts onto the $\mathrm{LB}$ film using an indirect method, to form a junction with symmetric electrodes. Using Al electrodes, they reported a single measurement for which $R(1.5 \mathrm{~V})=26$ (a positive value of $R$, according to our nomenclature). The authors acknowledged the presence of thin layers of $\mathrm{Al}_{2} \mathrm{O}_{3}$ on both electrodes, but because both electrodes were oxidized, the electrodes were still symmetric. Control experiments with LB films of arachidic acid $\left(\mathrm{H}_{3} \mathrm{C}\left(\mathrm{CH}_{2}\right)_{18} \mathrm{COOH}\right)$ showed no rectification, whether using $\mathrm{Al}$ or Au electrodes. ${ }^{29}$ The authors, therefore, concluded that the rectification observed for junctions containing the $\mathrm{D}^{+}-\sigma-\mathrm{A}^{-}$molecule had a molecular origin, but could not determine the mechanism of rectification. 
Table 1: The Magnitude and Sign of the Rectification Ratio Depends on the Terminal Moiety of the SAM

\begin{tabular}{|c|c|c|c|c|}
\hline Compound & $r$ (eq. 2) & $<\log |r|>$ & $R$ (eq. 3) & Molecular Diode? ${ }^{\mathrm{a}}$ \\
\hline $\mathrm{S}\left(\mathrm{CH}_{2}\right)_{11} \mathrm{Fc}_{2}$ & -0.0020 & $-2.70 \pm 0.54$ & -500 & Yes \\
\hline $\mathrm{S}\left(\mathrm{CH}_{2}\right)_{11} \mathrm{Fc}$ & -0.0093 & $-2.03 \pm 0.49$ & -100 & Yes \\
\hline $\mathrm{S}\left(\mathrm{CH}_{2}\right)_{9} \mathrm{Fc}$ & -0.11 & $-0.97 \pm 0.65$ & -10 & Yes \\
\hline $\mathrm{S}\left(\mathrm{CH}_{2}\right)_{6} \mathrm{Fc}\left(\mathrm{CH}_{2}\right)_{5} \mathrm{CH}_{3}$ & -1.2 & $0.10 \pm 0.23$ & 1.2 & No \\
\hline $\mathrm{S}\left(\mathrm{CH}_{2}\right)_{10} \mathrm{CH}_{3}$ & -1.5 & $0.18 \pm 0.17$ & 1.5 & $\mathrm{No}^{b}$ \\
\hline $\mathrm{S}\left(\mathrm{CH}_{2}\right)_{14} \mathrm{CH}_{3}$ & -2.3 & $0.35 \pm 0.40$ & 2.3 & $\mathrm{No}^{\mathrm{b}}$ \\
\hline $\begin{array}{l}\mathrm{S}\left(\mathrm{CH}_{2}\right)_{10} \mathrm{~S}- \\
\text { trimethylbenzoquinone }\end{array}$ & -1.9 & $0.29 \pm 0.22$ & 1.9 & No \\
\hline $\begin{array}{l}\mathrm{S}\left(\mathrm{CH}_{2}\right)_{10} \mathrm{~S}- \\
\text { methylnapthoquinone }\end{array}$ & -3.5 & $0.54 \pm 0.34$ & 3.5 & Inconclusive $^{c}$ \\
\hline $\mathrm{S}\left(\mathrm{CH}_{2}\right)_{10} \mathrm{CH}_{2} \mathrm{OH}$ & -2.5 & $0.40 \pm 0.32$ & 2.5 & No \\
\hline $\mathrm{S}\left(\mathrm{CH}_{2}\right)_{10} \mathrm{COOH}$ & -2.4 & $0.38 \pm 0.25$ & 2.4 & No \\
\hline
\end{tabular}

\footnotetext{
${ }^{\mathrm{a}}$ The text discusses whether the value of $R$ statistically distinguishable, according to a multiple comparison test, from both alkanethiolate controls.

${ }^{\mathrm{b}}$ These compounds are controls, and are, therefore, defined not to be molecular diodes. ${ }^{c}$ Although the value of $R$ for this compound was statistically distinguishable from those of both alkanethiolate controls, it is not large enough to qualify convincingly as a molecular diode.
} 
Ashwell et al. have worked to show that the Aviram-Ratner mechanism is indeed responsible for rectification in D-bridge-A molecules. They formed SAMs of two compounds - the first having an $\mathrm{A}^{+}$-bridge- $\mathrm{D}$ (the acceptor in this compound was cationic) structure $(R(1.0 \mathrm{~V})=5)$, and the second having a D-bridge-A structure $(R(1.0 \mathrm{~V})=-10--20) \smile$ on $\mathrm{Au}$ and showed that their rectification ratios had opposite signs. ${ }^{30}$ In both compounds, the $\mathrm{D}$ and A moieties were isolated from both electrodes by alkyl chains of equal length $\left(\mathrm{C}_{10}\right)$, in order to avoid any incidental asymmetry that might contribute to rectification. For the A-bridge-D structure, when the alkyl chain adjacent to the $\mathrm{D}$ moiety was removed, the rectification ratio increased ${ }^{30}$ by more than a factor of 3 , to $R(1.0 \mathrm{~V})=18$. This result indicates that, while the A-bridge-D moiety is responsible for some rectification, the position of the conjugated moieties relative to the electrodes can also be an important factor. We note that, when Ashwell et al. report large values of $R-$ such as $R(1.0 \mathrm{~V})=50-150$ for the $\mathrm{A}^{+}$-bridge-D structure just discussed, ${ }^{31}$ and $R(1.0$ V) $=3000$ for this same structure coupled to an organometallic counterion ${ }^{32}-$ these values are obtained from highly asymmetric junctions, in which the conjugated moieties are adjacent to one electrode, but separated from the other electrode by a $\mathrm{C}_{10}$ alkyl chain. Conclusions that rest on comparisons between two or more rectifiers are also much easier to evaluate with access to entire distributions of data (such as those we have shown here and in our previous publications), than when using single ("representative") measurements, or averaged values alone.

Within the last decade, Kornilovitch et al., ${ }^{33}$ Bratkovsky et al., ${ }^{34}$ Liu et al., ${ }^{35} \mathrm{Xu}$ et al., ${ }^{36}$ and Stokbro, ${ }^{33}$ have suggested that a D- $\sigma$-A structure is not required for molecular rectification, but that rectification can be achieved with a single, localized, accessible 
molecular orbital placed asymmetrically between two electrodes. To take one example, the rectifier proposed by Liu et al. incorporated a cobaltocene moiety, covalently bonded to Au electrodes, with a four-carbon alkyl chain on one side $\left(\mathrm{Au}-\mathrm{S}\left(\mathrm{CH}_{2}\right)_{4} \mathrm{Co}-\mathrm{S}-\mathrm{Au}, \mathrm{Co}=\right.$ cobaltocene). These (hypothetical) junctions are asymmetric: the cobaltocene moiety lies adjacent to one electrode, but separated from the other electrode by the alkyl chain. The authors simulated the electronic properties of this junction and predicted $R(0.5 \mathrm{~V})=10$.

Chang et al. ${ }^{37}$ attempted to construct a rectifier based on a single, accessible, asymmetrically placed molecular orbital. They contacted SAMs of 2-tetradecoxynaphth6-yl)propanethiol on Pt using a film of Ti deposited by e-beam evaporation, and observed very large rectification $\left(R=5 \times 10^{5}\right)$. It is likely, however, that this value does not result from the SAM, but from oxidation of the Ti electrode to form a Schottky barrier. McCreery et al. reported rectification ${ }^{38}$ in another junction with evaporated Ti electrodes, but later issued a correction ${ }^{39}$ after finding that oxidation of the Ti electrode in the evaporator had caused the observed rectification. Given the range of possible artifacts suggested by some of these papers, skepticism towards oxidizable electrodes is warranted, and is one motivation for us to address the issue of the $\mathrm{Ga}_{2} \mathrm{O}_{3}$ film on the surface of conical $\mathrm{Ga}_{2} \mathrm{O}_{3} / \mathrm{EGaIn}$ electrodes.

Recently, we and others have realized an experimental demonstration of a rectifier that incorporates a ferrocene group $-\mathrm{S}\left(\mathrm{CH}_{2}\right)_{11} \mathrm{Fc}(\mathrm{Fc}=$ ferrocene $)$ - and have given evidence that the rectification has a molecular origin ${ }^{23}$ and is dependent on asymmetric placement of the Fc moiety between the electrodes. ${ }^{22}$

Background: Evidence for Our Proposed Mechanism. We briefly describe here all of our relevant, published results on rectification in SAMs containing Fc and SAMs of 
Figure 1: Histograms of $\log |r|$ (eq. 2) for $\mathrm{Ag}^{\mathrm{TS}}-\mathrm{S}\left(\mathrm{CH}_{2}\right)_{11} \mathrm{Fc}_{2} / / \mathrm{Ga}_{2} \mathrm{O}_{3} / \mathrm{EGaIn}(\mathrm{A})$, $\mathrm{Ag}^{\mathrm{TS}}-\mathrm{S}\left(\mathrm{CH}_{2}\right)_{11} \mathrm{Fc} / / \mathrm{Ga}_{2} \mathrm{O}_{3} / \mathrm{EGaIn}(\mathrm{B}), \mathrm{Ag}^{\mathrm{TS}}-\mathrm{S}\left(\mathrm{CH}_{2}\right)_{9} \mathrm{Fc} / / \mathrm{Ga}_{2} \mathrm{O}_{3} / \mathrm{EGaIn}(\mathrm{C})$, $\mathrm{Ag}^{\mathrm{TS}}-\mathrm{S}\left(\mathrm{CH}_{2}\right)_{6} \mathrm{Fc}\left(\mathrm{CH}_{2}\right)_{5} \mathrm{CH}_{3} / / \mathrm{Ga}_{2} \mathrm{O}_{3} / \mathrm{EGaIn}(\mathrm{D}), \mathrm{Ag}^{\mathrm{TS}}-\mathrm{S}\left(\mathrm{CH}_{2}\right)_{10} \mathrm{CH}_{3} / / \mathrm{Ga}_{2} \mathrm{O}_{3} / \mathrm{EGaIn}(\mathrm{E})$, and $\mathrm{Ag}^{\mathrm{TS}}-\mathrm{S}\left(\mathrm{CH}_{2}\right){ }_{14} \mathrm{CH}_{3} / / \mathrm{Ga}_{2} \mathrm{O}_{3} / \mathrm{EGaIn}$ (F) junctions. Gaussian functions fitted to each histogram appear as black curves, and the values of $<\log |r|>$ and $R$ (eq. 3) determined from these functions, as well as the number of data $(N)$, are given beside each histogram. The dashed line is a guide for the eye placed at $\log |r|=0(R=1)$. The data in this Figure were originally published in reference 22; here, they have been plotted differently, in accordance with the definitions of $\log |r|$ and $R$ used in this paper. 


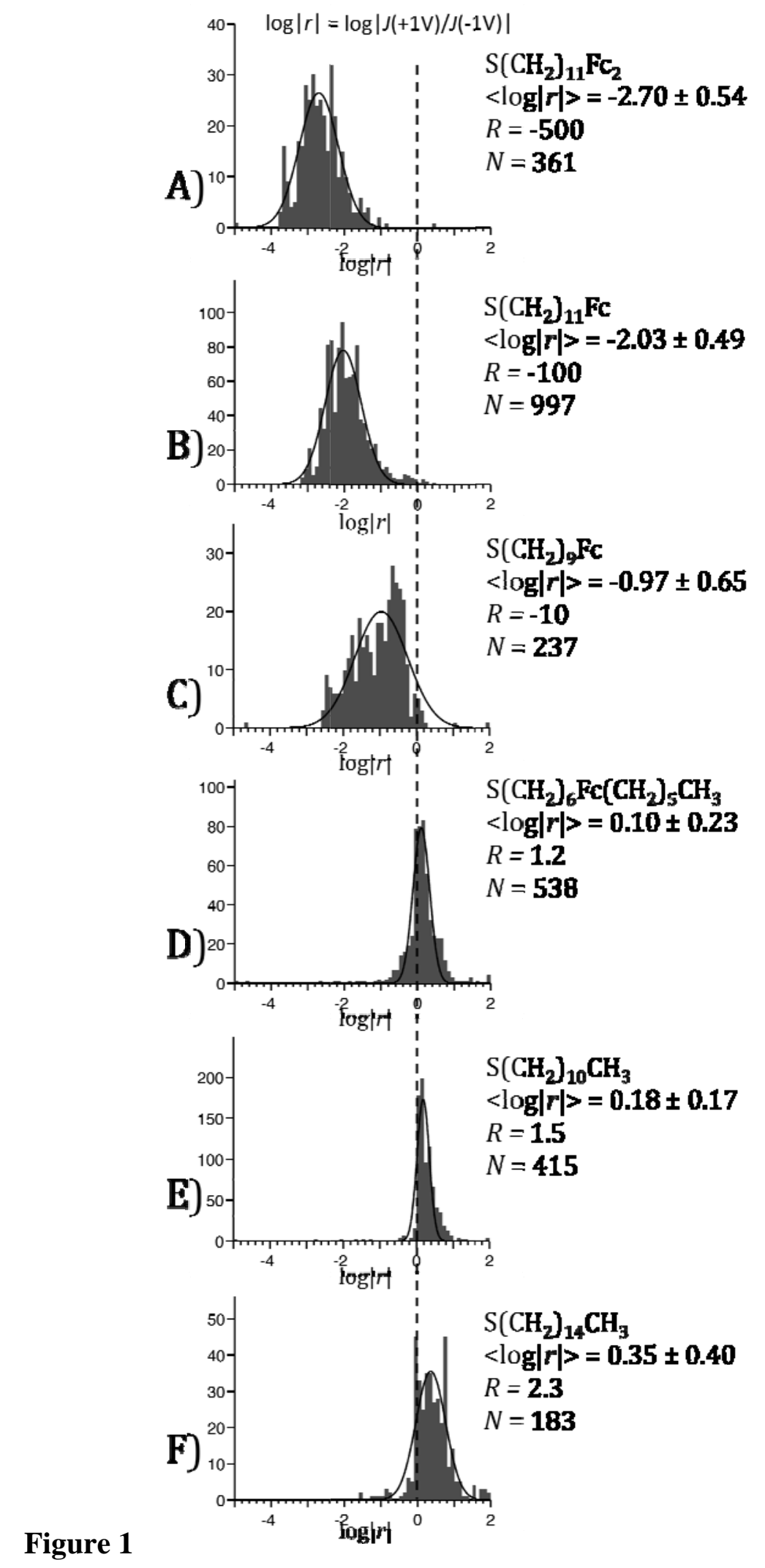


alkanethiols (used as controls). We previously published a detailed study of the mechanism of rectification ${ }^{22}$ in which we synthesized and measured several compounds containing $\mathrm{Fc}$, including $\mathrm{S}\left(\mathrm{CH}_{2}\right)_{11} \mathrm{Fc}_{2}$ (where $\mathrm{Fc}_{2}$ is bis-ferrocene), $\mathrm{S}\left(\mathrm{CH}_{2}\right)_{11} \mathrm{Fc}$, $\mathrm{S}\left(\mathrm{CH}_{2}\right)_{9} \mathrm{Fc}$, and $\mathrm{S}\left(\mathrm{CH}_{2}\right)_{6} \mathrm{Fc}\left(\mathrm{CH}_{2}\right)_{5} \mathrm{CH}_{3}$. Since we wish to discuss aspects of these experiments and data we have not discussed previously, and since the quality of the data is relevant to these discussions, we have included those (previously published) ${ }^{22}$ data in this paper: Figure 1 A-D show histograms of $\log |r|$ for these compounds; their values of $<\log |r|>$ and $R$ appear in the same figure, and in Table 1. We also measured junctions containing SAMs of alkanethiols $\left(\mathrm{S}_{\left(\mathrm{CH}_{2}\right)}\right)_{10} \mathrm{CH}_{3}$ and $\mathrm{S}\left(\mathrm{CH}_{2}\right)_{14} \mathrm{CH}_{3}$; Figure $1 \mathrm{E}$ and $\left.\mathrm{F}\right)-$ as controls, to show that rectification was due to the SAM, and not to other characteristics of the junction (for example, the $\mathrm{Ga}_{2} \mathrm{O}_{3} / \mathrm{EGaIn}$ electrode).

We used these data to support our proposed mechanism of rectification, shown schematically in Figure 2A for $\mathrm{S}\left(\mathrm{CH}_{2}\right)_{11} \mathrm{Fc}$. According to this mechanism, the placement of the highest occupied molecular orbital (HOMO) of ferrocene ( $\mathrm{Fc}$ ) adjacent to the $\mathrm{Ga}_{2} \mathrm{O}_{3} / E$ EaIn electrode - but separated from the Ag electrode by a $\mathrm{C}_{11}$ alkyl chain - fixes the position of the HOMO relative to the Fermi level of the $\mathrm{Ga}_{2} \mathrm{O}_{3} / \mathrm{EGaIn}$ electrode. When the EGaIn is biased positively, the HOMO of Fc remains below the Fermi levels of both electrodes, and is unable to participate in charge transport. When the EGaIn is biased negatively, however, the Fc HOMO rises to a position between the Fermi levels of the two electrodes and is able to participate in charge transport. At negative bias, when the Fc HOMO participates in charge transport, the width of the tunneling barrier is approximately the length of the $\mathrm{C}_{11}$ alkyl chain $(\sim 14.5 \AA)$. At positive bias, however, when the Fc HOMO cannot participate in charge transport, the width of the tunneling 
Figure 2: . Energy level diagrams showing the proposed mechanism of rectification. A) For SAMs of $\mathrm{S}\left(\mathrm{CH}_{2}\right)_{11} \mathrm{Fc}$, the Fc HOMO couples to the Fermi level of EGaIn and remains below it over the range of applied bias. Our mechanism, therefore, predicts higher current when EGaIn is biased negatively than when it is biased positively, because the $\mathrm{Fc} \mathrm{HOMO}$ can participate in charge transport under the former condition, but not the latter. B) For $\mathrm{SAMs}$ of $\mathrm{S}\left(\mathrm{CH}_{2}\right)_{6} \mathrm{Fc}\left(\mathrm{CH}_{2}\right)_{5} \mathrm{CH}_{3}$, the $\mathrm{Fc} \mathrm{HOMO}$ couples roughly equally to the Fermi levels of both electrodes and can, thus, participate in charge transport at both positive and negative bias. It does not rectify. C) In SAMs of 5, the naphthoquinone LUMO lies above the Fermi levels of the electrodes, and also couples to the EGaIn electrode. D) SAMs of $\mathrm{S}\left(\mathrm{CH}_{2}\right)_{10} \mathrm{CH}_{3}$ have no accessible molecular orbital to participate in charge transport and do not rectify. Idealized schematic representations of the corresponding tunneling junctions consisting of $\mathrm{Ag}^{\mathrm{TS}}$ bottom-electrodes, SAMs of $\mathrm{S}\left(\mathrm{CH}_{2}\right)_{11} \mathrm{Fc}(\mathrm{A}), \mathrm{S}\left(\mathrm{CH}_{2}\right)_{6} \mathrm{Fc}\left(\mathrm{CH}_{2}\right)_{5} \mathrm{CH}_{3}(\mathrm{~B})$, compound $5(\mathrm{C})$, and $\mathrm{S}\left(\mathrm{CH}_{2}\right)_{10} \mathrm{CH}_{3}(\mathrm{D})$, and $\mathrm{Ga}_{2} \mathrm{O}_{3} /$ EGaIn top-electrodes. 


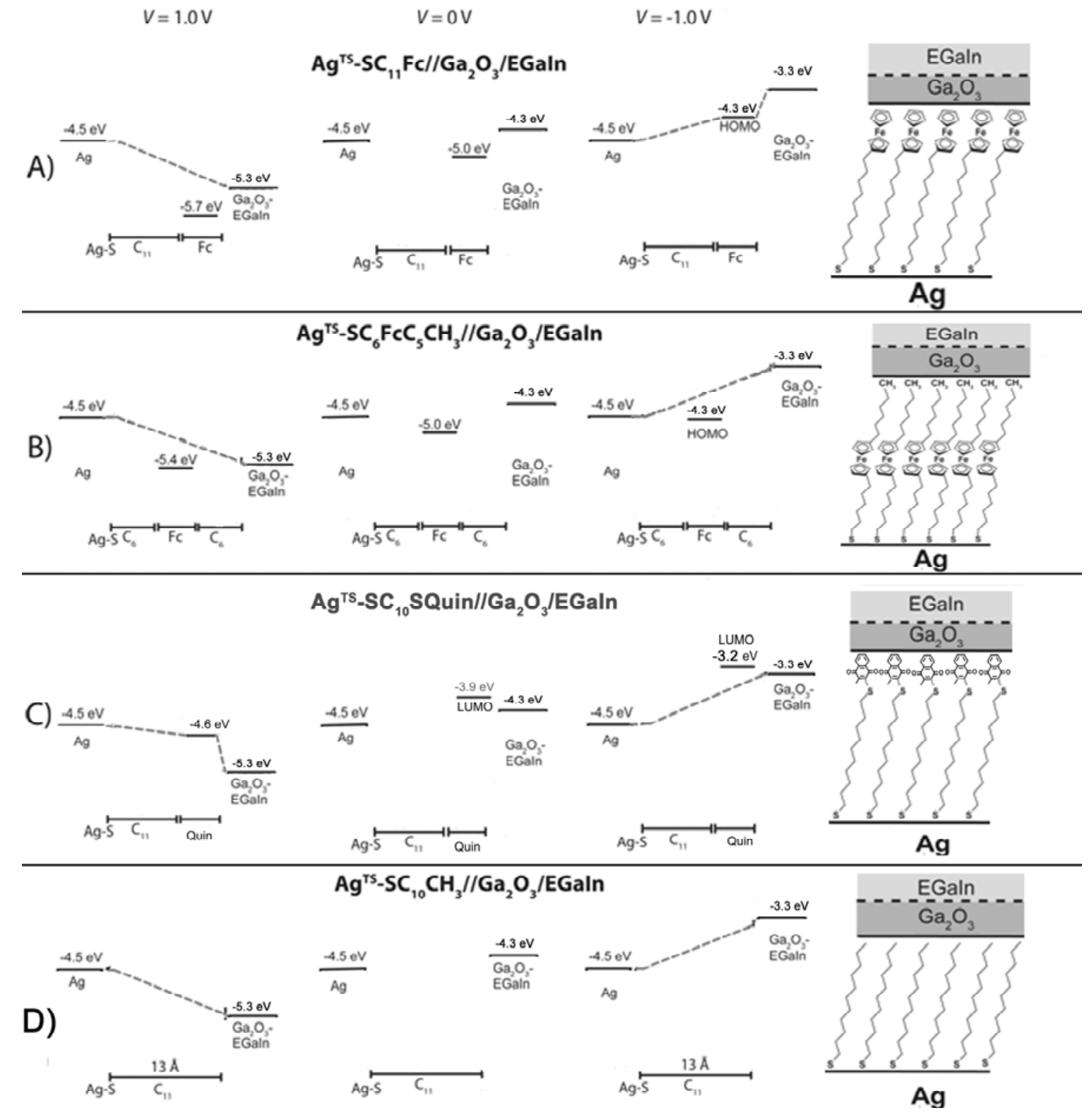

Figure 2 
barrier is defined by the length of the entire molecule $(\sim 19 \AA)$, including both the alkyl chain and the Fc moiety. Because the tunneling current density decreases exponentially as the width of the tunneling barrier increases, $J$ at negative bias is significantly greater than $J$ at positive bias; indeed, $\mathrm{Ag}^{\mathrm{TS}}-\mathrm{S}\left(\mathrm{CH}_{2}\right)_{11} \mathrm{Fc} / / \mathrm{Ga}_{2} \mathrm{O}_{3} / \mathrm{EGaIn}$ junctions rectify with $R \cong$ -100 (Figure 1B). The difference between $J(-1.0 \mathrm{~V})$ and $J(+1.0 \mathrm{~V})$ can be modeled quantitatively, using the simplified Simmons model, adapted to the composite structure of the rectifier. The Simmons model predicts different values for $J(-1.0 \mathrm{~V})$ (eq. 4) and $J(+1.0 \mathrm{~V})$ (eq. 5), due to the necessity of tunneling through the Fc moiety at the latter bias, but not the former.

$$
\begin{aligned}
& J(-1.0 \mathrm{~V})=J_{0} e^{-\beta_{a l k} d_{a l k}} \\
& J(+1.0 \mathrm{~V})=J_{0} e^{-\left(\beta_{a k k} d_{a k k}+\beta_{F C} C_{F C}\right)}
\end{aligned}
$$

Here, $\beta_{a l k}$ is the tunneling constant for the $\mathrm{C}_{11}$ alkyl chain (approximately $0.8 \AA^{-1}$, although this value does not affect $\log |r|$ ), and $d_{a l k}$ is the length (in $\AA$ ) of the $\mathrm{C}_{11}$ alkyl chain. Similarly, $\beta_{F C}$ is the tunneling constant for the Fc moiety (when the HOMO is not in resonance with the electrodes), and $d_{F c}$ is the length of the Fc moiety along the axis perpendicular to the planes of the electrodes. Given these relationships, and assuming that $J_{0}$ is the same at $-1.0 \mathrm{~V}$ and $+1.0 \mathrm{~V}$, it is possible to rewrite $\log |r|$, using eq. 6 , in a way that depends only on $\beta_{F C}$ and $d_{F c}$.

$$
\log |r|=-\log (e) \beta_{F c} d_{F c}
$$

If we use the value of $d_{F c}=4.5 \AA$ and assume that $\beta_{F c}=\beta_{a l k}\left(=0.8 \AA^{-1}\right.$; a questionable assumption, because the heights of the two tunneling barriers posed by the $\mathrm{C}_{11}$ alkyl chain and the $\mathrm{Fc}$ moiety are probably not the same), then eq. 6 predicts that $\log |r|=-1.6$. The observed $<\log |r|>$ of -2.0 has a slightly greater magnitude than the predicted value, 
but is within plausible agreement, given the several assumptions made. The direction of disagreement implies that either $d_{F C}>4.5 \AA$ or $\beta_{F C}>\beta_{a l k}$. Of the two options, the latter is more likely. Setting $\log |r|=-2.0$ and $d_{F C}=4.5 \AA$, and solving for $\beta_{F C}$ yields a value of $1.02 \AA^{-1}$.

According to this mechanism, increasing the difference between the effective widths of the tunneling barriers at negative and positive bias should increase the magnitude of $R$. We tested this prediction by attaching a second $\mathrm{Fc}$ moiety, in conjugation with the first $\mathrm{Fc}$ moiety, to the end of the molecule to produce $\mathrm{S}\left(\mathrm{CH}_{2}\right)_{11} \mathrm{Fc}_{2}$. Adding this second $\mathrm{Fc}$ moiety had only a small effect on the energy of the HOMO (raising from $-5.0 \mathrm{eV}$ to $-4.9 \mathrm{eV}$, still lower than the Fermi levels of both electrodes), but increased the total length of the molecule to $\sim 23 \AA$ ( $d_{F C}=8.5 \AA$, where in this case, $d_{F C}$ is the length of the $\mathrm{Fc}_{2}$ moiety). In accordance with the qualitative prediction of our mechanism, we determined $R=-500(<\log |r|>=-2.70 \pm 0.54)$ for this compound (Figure 1A). If we assume that the tunneling constant for $\mathrm{Fc}_{2}$ is the same as that derived above for $\mathrm{Fc}\left(\beta_{F C}=1.02 \AA^{-1}\right)$, eq. 6 predicts that $\mathrm{S}\left(\mathrm{CH}_{2}\right)_{11} \mathrm{Fc}_{2}$ should have $<\log |r|>=-3.78$; that is, the predicted rectification is more than one order of magnitude greater than the observed rectification.

A plausible rationalization of this difference would start with the fact that the predicted value of $\left\langle\log |r|>=-3.78\right.$ assumes that the $\mathrm{Fc}_{2}$ moiety adopts the most extended conformation possible - that is, the two Fc groups lie along the axis of the molecular backbone. Because SAMs are not perfect two-dimensional crystals, rotation probably occurs around the bond connecting the two $\mathrm{Fc}$ moieties to each other (i.e. the $\mathrm{Fc}_{2}$ group "folds over"), or the bond connecting the $\mathrm{Fc}_{2}$ group to the $\mathrm{C}_{11}$ alkyl chain (i.e. the $\mathrm{Fc}_{2}$ group tilts away from the axis of the molecular backbone). Either, or both, rotations 
would decrease the separation between the electrodes, relative to the conformation in which the $\mathrm{Fc}_{2}$ group is maximally extended. In fact, if we substitute the observed value of $<\log |r|>$ into eq. 6 and allow $d_{F C}$ to vary (with $\beta_{F C}=1.02 \AA^{-1}$ ), we estimate $d_{F C}=6.07$ $\AA$. This value lies between that of a single Fc moiety (4.5 $\AA$ ) and a fully extended $\mathrm{Fc}_{2}$ moiety ( $8.5 \AA$ ), and may represent the average length of the set of conformations adopted by the $\mathrm{Fc}_{2}$ group.

On the other hand, the difference between the predicted and observed values of $<\log |r|>$ for $\mathrm{S}\left(\mathrm{CH}_{2}\right)_{11} \mathrm{Fc}_{2}$ may reflect a deficiency in the quantitative model (eq. $4-6$ ); this deficiency nonetheless does not affect the integrity of the mechanism from which it is derived. For example, temperature-dependent measurements (described below in this section) establish that the mechanism of rectification involves a change, at sufficiently negative bias, from tunneling alone (through the entire $\mathrm{S}\left(\mathrm{CH}_{2}\right)_{11} \mathrm{Fc}$ molecule) to tunneling (through the $\mathrm{C}_{11}$ alkyl chain) and hopping (between the Fc moiety and the $\mathrm{Ga}_{2} \mathrm{O}_{3} / \mathrm{EGaIn}$ electrode). Our proposed mechanism incorporates this observation, but the quantitative model in eq. $4-6$ does not: it only accounts for tunneling, not hopping. If hopping is not substantially faster than tunneling, or if the rate of hopping (i.e. the activation energy) differs for the $\mathrm{Fc}$ and $\mathrm{Fc}_{2}$ moieties, then the quantitative predictions of the model will fail, even though the underlying mechanism is correct. In any case, although our mechanism has yet to be vindicated by successful quantitative predictions, it does successfully rationalize trends qualitatively connecting values of $R$ with the structure of the molecules making up the SAM.

To confirm the molecular origin of rectification in these Fc-terminated rectifiers, we employed three compounds as controls: $\mathrm{S}\left(\mathrm{CH}_{2}\right){ }_{10} \mathrm{CH}_{3}, \mathrm{~S}\left(\mathrm{CH}_{2}\right){ }_{14} \mathrm{CH}_{3}$, and 
$\mathrm{S}\left(\mathrm{CH}_{2}\right)_{6} \mathrm{Fc}\left(\mathrm{CH}_{2}\right)_{5} \mathrm{CH}_{3}$. The first two controls-alkanethiols having the same length as the $\mathrm{C}_{11}$ alkyl chain and the entire $\mathrm{S}\left(\mathrm{CH}_{2}\right)_{11} \mathrm{Fc}$ molecule, respectively - tested the prediction that SAMs without an accessible molecular orbital should not rectify. For $\mathrm{S}\left(\mathrm{CH}_{2}\right)_{10} \mathrm{CH}_{3}$, we measured $R=1.5$ (Figure 1E), and for $\mathrm{S}\left(\mathrm{CH}_{2}\right)_{14} \mathrm{CH}_{3}$, we measured $R=2.3$ (Figure $1 F)$. We found that these values do differ slightly, but statistically significantly, ${ }^{22}$ from unity, and from each other. We note, however, that whatever unknown factor causes slight rectification in SAMs of alkanethiols produces values of $R$ that are positive, whereas $R$ is negative for Fc-terminated SAMs. The third control, $\mathrm{S}\left(\mathrm{CH}_{2}\right)_{6} \mathrm{Fc}\left(\mathrm{CH}_{2}\right)_{5} \mathrm{CH}_{3}$, was designed to test the prediction of our mechanism that a compound incorporating a $\mathrm{Fc}$ moiety, but lacking any asymmetry (i.e. with the $\mathrm{Fc}$ moiety placed in the middle of the SAM, flanked by alkyl chains of equal length) should not rectify, because rectification arises from the preferential coupling of the $\mathrm{Fc}$ moiety to one electrode over the other. Indeed, we determined that, for $\mathrm{S}\left(\mathrm{CH}_{2}\right)_{6} \mathrm{Fc}\left(\mathrm{CH}_{2}\right)_{5} \mathrm{CH}_{3}, R(1.0 \mathrm{~V})=1.2$ (Figure 1D); this value is quite close to unity, and has the opposite sign from those of $\mathrm{S}\left(\mathrm{CH}_{2}\right)_{11} \mathrm{Fc}$ and $\mathrm{S}\left(\mathrm{CH}_{2}\right)_{11} \mathrm{Fc}_{2}$. These controls established that i) a molecular orbital is required for rectification, and ii) a single molecular orbital must be located asymmetrically within the junction in order to rectify.

In another prior publication, ${ }^{24}$ we used measurements of $J(\mathrm{~V})$ as a function of temperature $(T$, in $\mathrm{K})$ in order to elucidate the mechanism of rectification in SAMs of $\mathrm{S}\left(\mathrm{CH}_{2}\right)_{11} \mathrm{Fc}$. These experiments yielded two important results. i) Charge transport through junctions of the form $\mathrm{Ag}^{\mathrm{TS}}-\mathrm{S}\left(\mathrm{CH}_{2}\right)_{\mathrm{n}-1} \mathrm{CH}_{3} / / \mathrm{Ga}_{2} \mathrm{O}_{3} / \mathrm{EGaIn}$ showed negligible temperature dependence for $\mathrm{n}=12,14,16$, and 18 . This observation indicates that tunneling, as expected, is the dominant mechanism of charge transport through junctions 
incorporating SAMs of alkanethiols. ii) At sufficiently negative bias $(V<-0.6 \mathrm{~V})$, the rate of charge transfer through SAMs of $\mathrm{S}\left(\mathrm{CH}_{2}\right)_{11} \mathrm{Fc}$ decreased with decreasing temperature, whereas at all other biases $(V>-0.6 \mathrm{~V})$, charge transport was independent of temperature. The temperature-dependent charge transport at negative bias conformed to the Arrhenius relationship (a straight line on a plot of $\ln (J)$ vs. 1/T), and thus implied a hopping mechanism, with an activation energy of $78 \mathrm{meV}$. Our mechanism predicts that, at sufficiently negative bias, the Fc HOMO should become able to participate in classical charge transport (as opposed to tunneling). We interpreted the observation of thermally activated charge transport at $V<-0.6 \mathrm{~V}$ as confirmation that $\mathrm{Fc} \mathrm{HOMO}$ is involved in classical charge transport (i.e. hopping) at negative bias, but not at positive bias.

Our proposed mechanism of rectification - the asymmetric placement of a molecular orbital between two electrodes - successfully predicts the effect, on $R$, of several changes in the molecular structure of the rectifier. This mechanism finds further validation through temperature-dependent studies showing hopping (between the Fc moiety and the $\mathrm{Ga}_{2} \mathrm{O}_{3} / \mathrm{EGaIn}$ electrode) at negative bias, but not at positive bias. While we believe that this evidence is enough to justify confidence in our mechanism, we present, in this paper, further experimental confirmation of this mechanism, as well as evidence against alternative mechanisms, especially those involving the $\mathrm{Ga}_{2} \mathrm{O}_{3}$ film.

\section{Experimental Design}

Choice of Compounds. Our choice of molecules with $\mathrm{Fc}$ and $\mathrm{Fc}_{2}$ moieties, and our choice of alkanethiols, are explained in a previous publication. ${ }^{22}$ In addition to the compounds already reported previously, we chose to synthesize and measure two classes 
Scheme 1: Synthesis of quinone and TCNQ-terminated alkane thiols.

Trimethylhydroquinone 1 was oxidized to the corresponding $p$-quinone with (diacetoxyiodo)benzene. Addition of 1,10-decanedithiol (3) resulted in formation of quinone 2 after conjugate addition and reoxidation by another equivalent of starting material, as has been reported. ${ }^{40,41}$ An excess of the dithiol was used to suppress the formation of S,S-bisarylated by-products (disulfides). The synthesis of napthylquinone 5 was analogously performed beginning with commercially available menadione (4). Yields are given in the Supporting Information. 


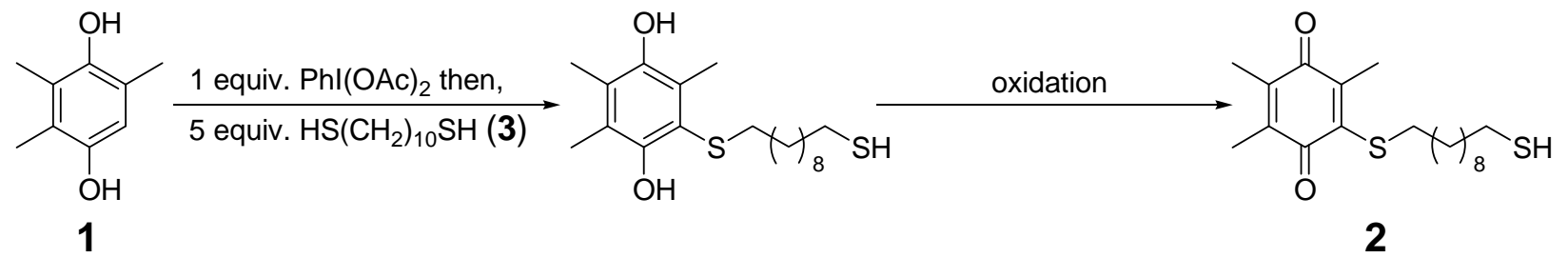

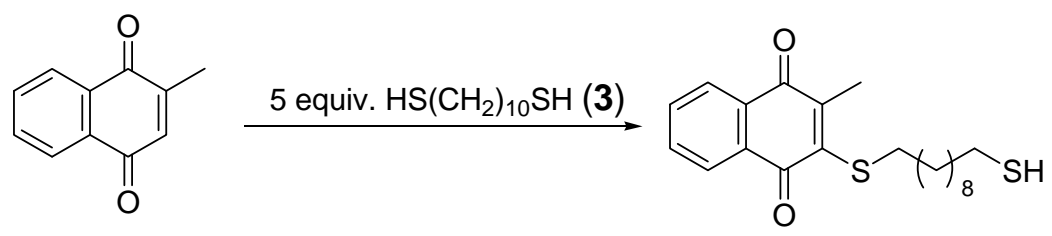

4

5 
of compounds: i) those with conjugated terminal groups having lowest unoccupied molecular orbitals (LUMOs) slightly above the Fermi levels of the electrodes $(-4.3--4.5$ $\mathrm{eV}),{ }^{19}$ and ii) those with polar terminal groups $(\mathrm{COOH}$ and $\mathrm{OH})$.

SAMs terminated by conjugated moieties with accessible HOMOs $\left(\mathrm{S}_{(\mathrm{CH}}\right)_{11} \mathrm{Fc}_{2}$, $\mathrm{S}\left(\mathrm{CH}_{2}\right)_{11} \mathrm{Fc}$, and $\left.\mathrm{S}\left(\mathrm{CH}_{2}\right)_{9} \mathrm{Fc}\right)$ slightly below the Fermi levels of the electrodes exhibit large, negative values of $R$. Our mechanism of rectification predicts that substituting a LUMO for the HOMO should change the sign of $R$. To test this prediction, we chose two molecules (Scheme 1) with terminal groups based on benzoquinone and modified with electron-withdrawing groups. Compound 2 is terminated by a trimethylbenzoquinone, and compound 5 is terminated by a methylnapthoquinone. We attached each of these moieties, via a thioether, to an alkanethiol chain with a total length of 12 atoms (including both sulfur atoms), in order to mimic the structures of $\mathrm{S}\left(\mathrm{CH}_{2}\right)_{11} \mathrm{Fc}$ and $\mathrm{S}\left(\mathrm{CH}_{2}\right)_{11} \mathrm{Fc}_{2}$ as closely as possible.

We also desired to test the effect, on charge transport and rectification, of polar terminal groups without an accessible molecular orbital. For this reason, we selected a carboxylic acid and a primary alcohol. We designed the length of the alkanethiol tail so that we could compare three compounds of the form $\mathrm{S}\left(\mathrm{CH}_{2}\right)_{10} \mathrm{R}$, where $\mathrm{R}=\mathrm{CH}_{3}, \mathrm{COOH}$, and $\mathrm{CH}_{2} \mathrm{OH}$.

Statistical Analysis of Rectification. Because many statistical analyses presume normal distributions, ${ }^{42}$ and because $r$ is approximately log-normally distributed, ${ }^{22,23}$ we analyzed distributions of $\log |r|$, rather than $r$. We did not directly analyze distributions of $R$, because $R$ is discontinuous (i.e. it is impossible to have values of $R$ between -1 and 1 ), 
and therefore difficult to analyze statistically. Detailed descriptions of our procedure for plotting histograms of $\log |r|$ and fitting them with Gaussians are given elsewhere. ${ }^{21,22,23}$

\section{Results}

SAMs with Redox-Active Terminal Groups. We synthesized two compounds (scheme 1: 2 and 5) having redox-active terminal groups with lowest unoccupied molecular orbitals (LUMOs) having energies close to, but greater than, the Fermi levels of the electrodes $(\mathrm{EGaIn} \approx-4.3 \mathrm{eV}, \mathrm{Ag} \approx-4.5 \mathrm{eV}) .^{43,44,45}$ The synthesis of these compounds is described in the Supporting Information. We do not know the exact energies of the LUMOs of these compounds, but we do know that the LUMO of 2 is higher in energy than the LUMO of 5, because the addition of a second aromatic ring increases the electron affinity of the moiety. Using procedures described previously, ${ }^{21,22,23}$ we formed SAMs of these compounds, and used conical tips of $\mathrm{Ga}_{2} \mathrm{O}_{3} / \mathrm{EGaIn}$ to fabricate and measure junctions of the form $\mathrm{Ag}^{\mathrm{TS}}-\mathrm{SR} / / \mathrm{Ga}_{2} \mathrm{O}_{3} / \mathrm{EGaIn}$. We measured $J$ through these junctions over a range of applied bias from $V=-1.2 \mathrm{~V}$ to $1.2 \mathrm{~V}$. (Because a range of $V=$ $-1.0 \mathrm{~V}$ to $1.0 \mathrm{~V}$ was insufficient to observe rectification for SAMs of $\mathbf{2}$ and $\mathbf{5}$, we were forced to expand the range of applied bias slightly, from $\pm 1.0 \mathrm{~V}$ to $\pm 1.2 \mathrm{~V}$.) The values reported in the literature for the Fermi levels of $\mathrm{Ag}(\sim-4.5 \mathrm{eV})$ and EGaIn $(\sim-4.3 \mathrm{eV})$ are slightly different, and the actual Fermi levels of the electrodes in the junctions might differ by either more or less than $\sim 0.3 \mathrm{eV}$, due to any number of factors (the presence of a $\mathrm{Ga}_{2} \mathrm{O}_{3}$ film on EGaIn, the van der Waals interface between $\mathrm{Ga}_{2} \mathrm{O}_{3} / \mathrm{EGaIn}$ and the SAM, the Ag-S bond). 
Figure 3: Energy-level diagram for junctions containing SAMs of compounds 2 and 5 (scheme 1). Because the terminal moiety of 5 is more electron-withdrawing than that of 2, the LUMO of 5 lies closer to the Fermi levels of the electrodes than that of $\mathbf{2}$. The energies of the LUMOs of $\mathbf{2}$ and $\mathbf{5}$ are approximate, but their relative positions are accurate. The heights of the tunneling barriers for the alkyl chain and the van der Waals interface have not been measured in our junctions, and may be quite different from what are shown. 


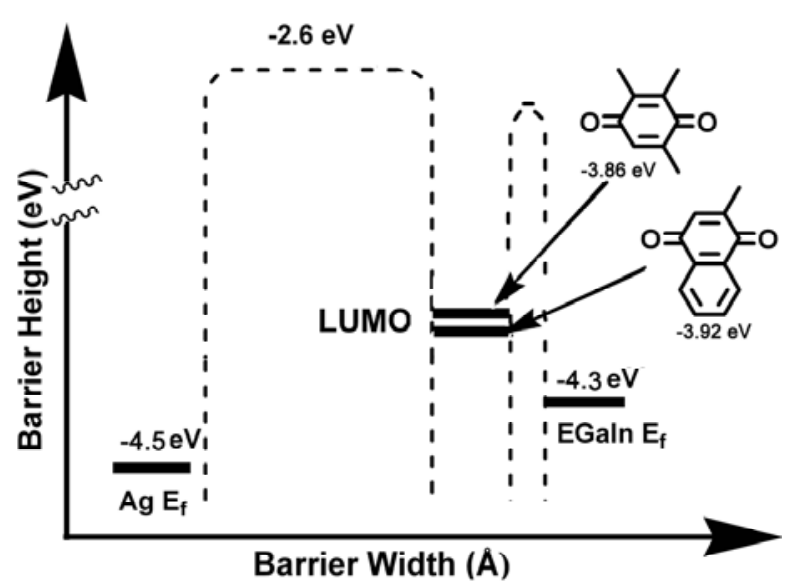

Fig. 3 
Figure 4: Histograms of $\log |r|$ (eq. 2) for junctions containing (A) SAMs of $\mathrm{S}\left(\mathrm{CH}_{2}\right)_{10} \mathrm{CH}_{3}$ and compounds with redox-active terminal groups: (B) naphthoquinone-terminated compound 5, (C) benzoquinone-terminated compound 2, and (D) $\mathrm{S}\left(\mathrm{CH}_{2}\right)_{11} \mathrm{Fc}$. Definitions of $\log |r|$ (eq. 2) and $R$ (eq. 3) appear in the text. Solid black curves give the Gaussian functions fitted to each histogram. We note that the SAMs of 2, and 5, whose histograms appear in ( $\mathrm{B}$ and $\mathrm{C})$, had to be measured at a bias range of $\pm 1.2 \mathrm{~V}$ in order to observe rectification. SAMs of $\mathrm{S}\left(\mathrm{CH}_{2}\right)_{11} \mathrm{Fc}$ were also stable up to $\pm 1.2 \mathrm{~V}$ and continued to rectify at this bias range ( $R$ was roughly unchanged). The dotted line is a guide for the eye at $\log |r|=0(R=1)$. 


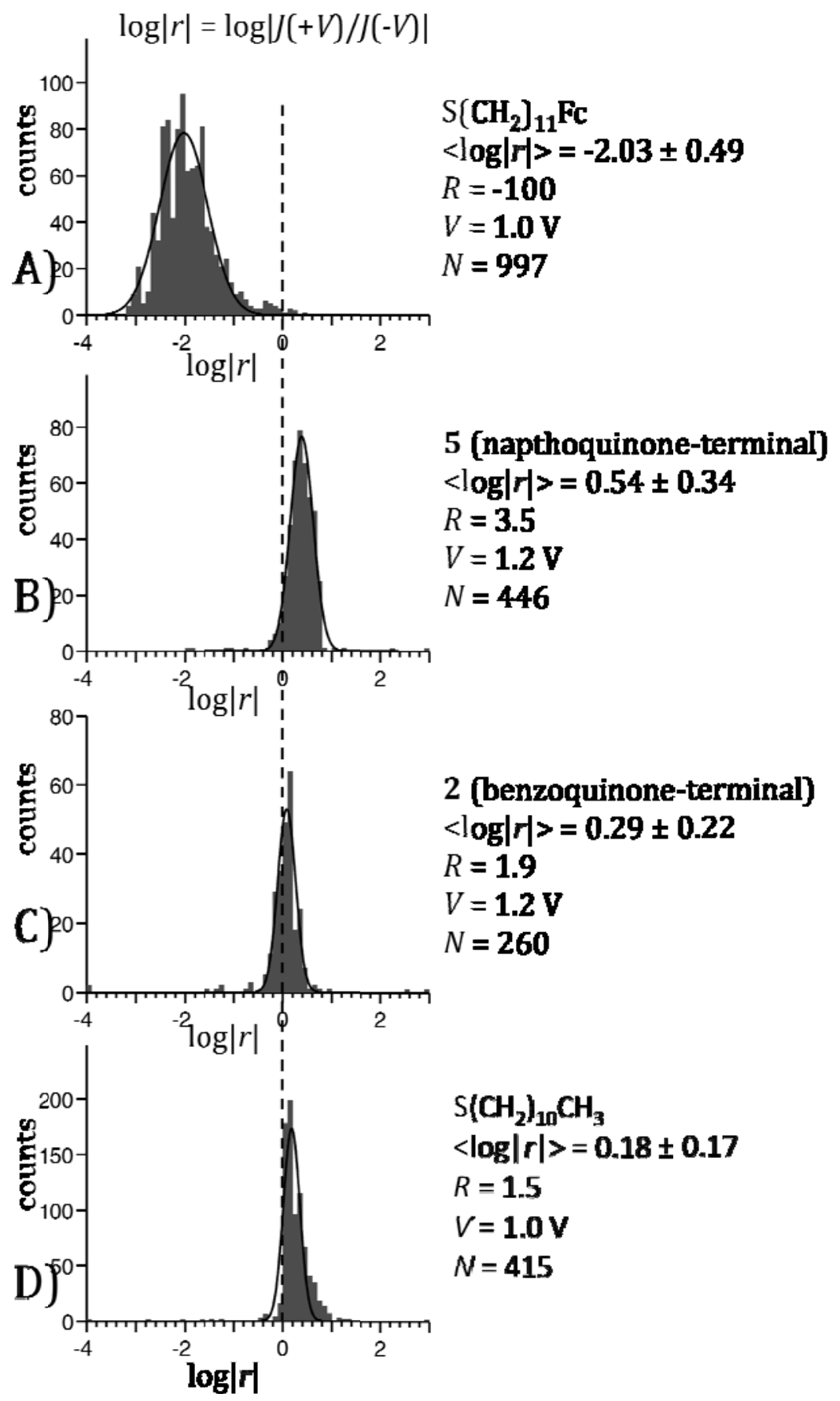

Figure 4 
If the Fermi level of the $\mathrm{Ag}^{\mathrm{TS}}$ electrode in the actual junction were still lower than that of the $\mathrm{Ga}_{2} \mathrm{O}_{3} / \mathrm{EGaIn}$ electrode, then this difference would increase the positive voltage necessary to bring the LUMO of $\mathbf{2}$ or $\mathbf{5}$ into resonance with the Fermi levels of the electrodes (Figure 3). By contrast, this situation would actually reduce the negative voltage necessary to bring the HOMO of Fc into resonance. In any case, we note that, based on a small set of measurements of $\mathrm{S}\left(\mathrm{CH}_{2}\right)_{11} \mathrm{Fc}$ over the range of $\mathrm{V}=-1.2 \mathrm{~V}$ to 1.2 $\mathrm{V}$, the value of $R$ at $\pm 1.2 \mathrm{~V}$ does not differ substantially from the value of $R$ at $1.0 \mathrm{~V}$. We believe, therefore that comparisons between $R(1.0 \mathrm{~V})$ for $\mathrm{S}\left(\mathrm{CH}_{2}\right)_{11} \mathrm{Fc}$, and $R(1.2 \mathrm{~V})$ for 2 and 5, are valid. Figure 4 contains histograms of $\log |r|$ for various compounds, including 2 and 5 (at a bias of $\pm 1.2 \mathrm{~V}$ ), as well as $\mathrm{S}\left(\mathrm{CH}_{2}\right)_{11} \mathrm{Fc}$ and $\mathrm{S}\left(\mathrm{CH}_{2}\right)_{10} \mathrm{CH}_{3}$ (at a bias of \pm 1.0 V), for comparison.

SAMs with Polar Terminal Groups. We have also formed junctions incorporating SAMs of two compounds with polar, non-redox-active terminal groups: $\mathrm{S}\left(\mathrm{CH}_{2}\right)_{10} \mathrm{CH}_{2} \mathrm{OH}$ (11-mercapto-1-undecanol) and $\mathrm{S}\left(\mathrm{CH}_{2}\right)_{10} \mathrm{COOH}$ (11-thioundecanoic acid). Both compounds are commercially available (Sigma Aldrich). We measured $J$ through these junctions over a range of applied bias from $V=-1.0 \mathrm{~V}$ to $1.0 \mathrm{~V}$. Histograms of $\log |r|$, at $V$ $= \pm 1.0 \mathrm{~V}$, for these compounds appear in Figure 5, again with $\mathrm{S}\left(\mathrm{CH}_{2}\right)_{11} \mathrm{Fc}$ and $\mathrm{S}\left(\mathrm{CH}_{2}\right)_{10} \mathrm{CH}_{3}$ for comparison. The values of $\mathrm{R}(1.0 \mathrm{~V})$ for $\mathrm{S}\left(\mathrm{CH}_{2}\right)_{10} \mathrm{CH}_{2} \mathrm{OH}$ and $\mathrm{S}\left(\mathrm{CH}_{2}\right)_{10} \mathrm{COOH}$ were 2.5 and 2.4 , respectively; these values are statistically distinguishable from $R=1$, according to a t-test ${ }^{42}$ (see next section).

Statistical Significance of Rectification. It is necessary to assess the statistical significance of the values of $R$ in Table 1 by asking two questions: i) is each value of $R$ statistically distinguishable from $R=1$ ? and ii) is each value of $R$ statistically distinct 
Figure 5: Histograms of $\log |r|$ (eq. 2) for junctions containing SAMs of $\mathrm{S}\left(\mathrm{CH}_{2}\right)_{10} \mathrm{CH}_{3}$ (A), two polar terminal groups: $\mathrm{S}\left(\mathrm{CH}_{2}\right)_{10} \mathrm{CH}_{2} \mathrm{OH}(\mathrm{B})$ and $\mathrm{S}\left(\mathrm{CH}_{2}\right)_{10} \mathrm{COOH}(\mathrm{C})$, and $\mathrm{S}\left(\mathrm{CH}_{2}\right)_{11} \mathrm{Fc}(\mathrm{D})$. Definitions of $\log |r|$ (eq. 2) and $R$ (eq. 3) appear in the text. Solid black curves indicate Gaussian functions fitted to each histogram. The dotted line is a guide for the eye at $\log |r|=0(R=1)$. 


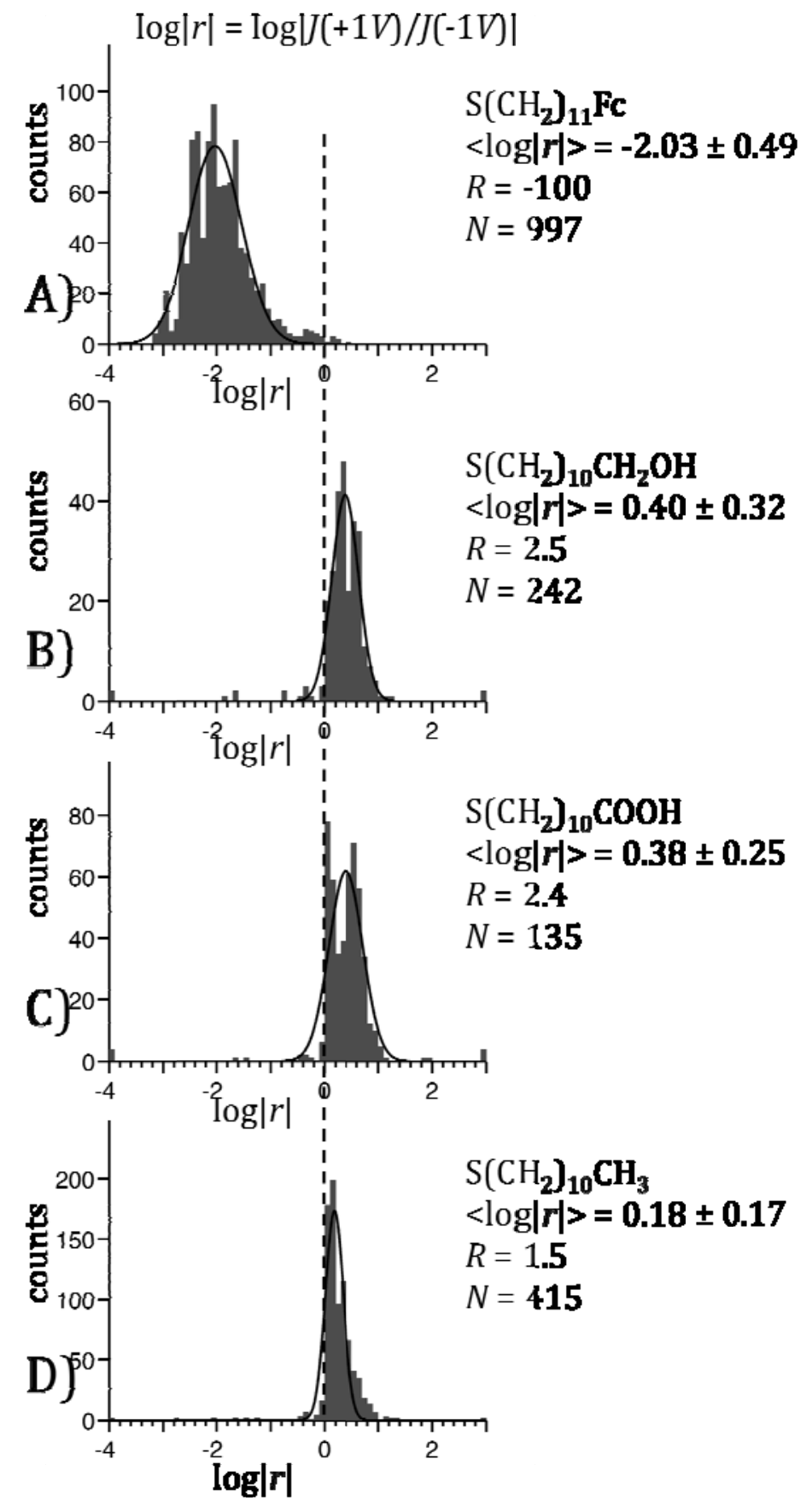

Figure 5 
from the values of $R$ for other compounds (especially the controls that lack molecular asymmetry: $\mathrm{S}\left(\mathrm{CH}_{2}\right){ }_{10} \mathrm{CH}_{3}$ and $\left.\mathrm{S}\left(\mathrm{CH}_{2}\right)_{14} \mathrm{CH}_{3}\right)$ ? Statistical tests exist to answer these questions, ${ }^{42}$ and, since these tests operate on variables with continuous probability distributions (i.e. not $R$ ), we applied them to the values of $\log |r|$ for the various compounds. Finding a statistically significant value (or difference between values) of $<\log |r|>$ is, nonetheless, equivalent to finding a statistically significant result for $R$. A value of $R$ that is statistically significant (i.e. distinguishable from $R=1$ ), in turn, implies an equivalent statistical significance for the sign of $R$.

To answer the first question, we performed t-tests on the distributions of $\log |r|$ for each compound to determine the probability $(p)$ of the null hypothesis: that a distribution was derived from a population with zero mean (i.e. that the value of $<\log |r|>$ was zero). All of these tests rejected the null hypothesis at well above the $95 \%$ confidence level (the highest $p$ obtained was $7 \times 10^{-6}$, for $\mathrm{S}\left(\mathrm{CH}_{2}\right)_{6} \mathrm{Fc}\left(\mathrm{CH}_{2}\right)_{5} \mathrm{CH}_{3}$; the rest were many orders of magnitude lower). This result implies that junctions containing every compound in Table 1 can be considered rectifying in the sense of giving rise to statistically significant rectification. We are primarily concerned, however, not with identifying which junctions rectify, but rather identifying which SAMs rectify. For some types of junctions (e.g. those containing alkanethiolates), the observed rectification, although statistically significant, almost certainly arises from something other than the SAM (we discuss several possible origins of the values of $R$ between $1.2-2.5$ in the "Discussion" section).

In determining which SAMs rectify, the second question - does the value of $R$ for a compound differ from the values of $R$ for other compounds, especially those of controls is much more informative than the first. In order to answer this question, we used a 
Figure 6: Results of a multiple comparison test, performed on the distributions of $\log |r|$ for all ten compounds reported in this paper. For each compound, the vertical dash represents the value of $<\log |r|>$ (Table 1) determined from the Gaussian fit to the histogram of $\log |r|$, and the horizontal bar represents the confidence interval for the value, calculated by the test. Arrows point to the confidence intervals of the two alkanethiolate controls, and vertical dotted lines indicate the range encompassing both confidence intervals of the alkanethiolate controls. The multiple comparison test is designed such that, if the confidence intervals of any two values of $<\log |r|>$ do not overlap, then the difference between those values is statistically significant. 


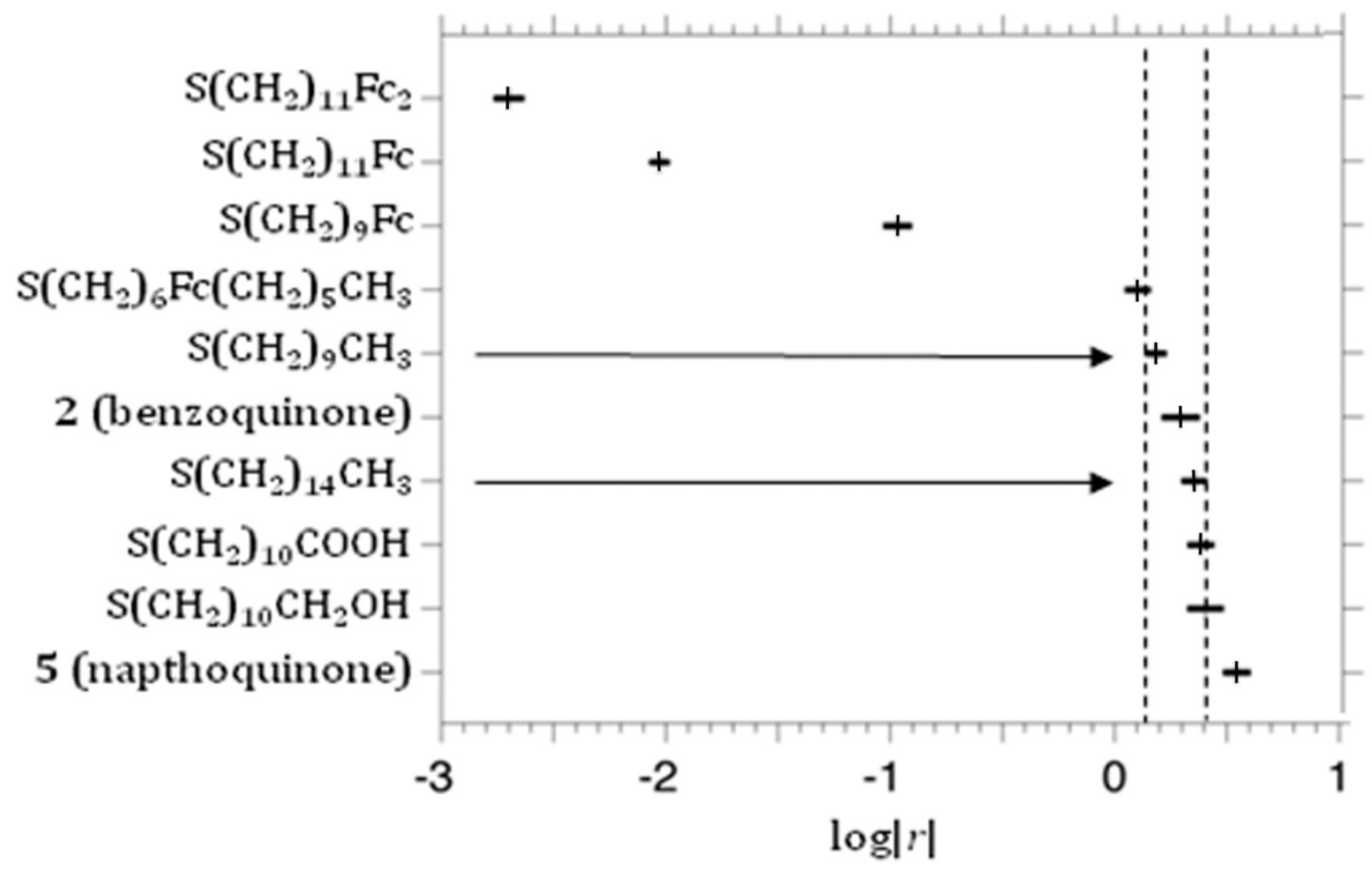

Figure 6: 
multiple comparison test, which compares the distributions of $\log |r|$ for all compounds simultaneously, using a procedure similar to a t-test. ${ }^{42,46,47}$ The multiple comparison test shows (at the $95 \%$ confidence level) whether, for example, the value of $R$ for $\mathrm{S}\left(\mathrm{CH}_{2}\right)_{11} \mathrm{Fc}$ is statistically distinguishable from the values of $R$ for other compounds. Figure 6 graphically represents the results of the multiple comparison test. Each bar in Figure 6 gives the confidence interval for a particular compound; if the bars of two compounds overlap, then their values of $R$ are not statistically distinguishable from one another. If two bars in Figure 6 do not overlap, however, then the values of $R$ for the corresponding two compounds are statistically different, at the $95 \%$ confidence level. According to this test, four compounds- $\mathrm{S}\left(\mathrm{CH}_{2}\right)_{11} \mathrm{Fc}_{2}, \mathrm{~S}\left(\mathrm{CH}_{2}\right)_{11} \mathrm{Fc}, \mathrm{S}\left(\mathrm{CH}_{2}\right)_{9} \mathrm{Fc}$, and compound 5-have values of $R$ that are statistically distinct from those of every other compound, including both alkanethiolate controls $\left(\mathrm{S}_{(}\left(\mathrm{CH}_{2}\right)_{10} \mathrm{CH}_{3}\right.$ and $\left.\mathrm{S}\left(\mathrm{CH}_{2}\right)_{14} \mathrm{CH}_{3}\right)$. This test confirms that the compounds terminated by $\mathrm{Fc}$ and $\mathrm{Fc}_{2}$ are, indeed, molecular diodes. While compound 5 also rectifies in a manner that is statistically distinguishable from other compounds, we hesitate to label $\mathbf{5}$ as a molecular diode, because although it is possible that rectification for compound 5 is molecular in origin, the value of $R=3.5$ is too small to be convincing. Hereafter, we will, therefore, use the term "molecular diode" only in reference to $\mathrm{S}\left(\mathrm{CH}_{2}\right)_{9} \mathrm{Fc}, \mathrm{S}\left(\mathrm{CH}_{2}\right)_{11} \mathrm{Fc}$, and $\mathrm{S}\left(\mathrm{CH}_{2}\right)_{11} \mathrm{Fc}_{2}$.

Comparison of Distributions of $\log |J|$ vs. Those of $\log |r|$. In the Introduction, we discussed the advantages of using rectification, instead of $J$ : rectification is a selfreferencing measurement that is insensitive to factors that vary from junction to junction. Figure 7 compares histograms of $\log \left|J /\left(\mathrm{A} / \mathrm{cm}^{2}\right)\right|$ against histograms of $\log |r|$ for three compounds: $\mathrm{S}\left(\mathrm{CH}_{2}\right)_{11} \mathrm{Fc}, 5$ (the naphthoquinone-terminated rectifier), and $\mathrm{S}\left(\mathrm{CH}_{2}\right)_{14} \mathrm{CH}_{3}$. 
Figure 7: Comparison of $\log \left|\mathrm{J} /\left(\mathrm{A} / \mathrm{cm}^{2}\right)\right|$ and $\log |r|$ for three compounds: $\mathrm{S}\left(\mathrm{CH}_{2}\right)_{11} \mathrm{Fc}$ (left column), $5\left(\mathrm{~S}\left(\mathrm{CH}_{2}\right)_{8} \mathrm{~S}\right.$-naphthoquinone, center column), and $\mathrm{S}\left(\mathrm{CH}_{2}\right)_{14} \mathrm{CH}_{3}$ (right column). Within each column, the top two histograms show $\log \left|J /\left(\mathrm{A} / \mathrm{cm}^{2}\right)\right|$ at $-V$ and $V$, respectively (where $V$ is the bias at which $R$ was determined). The bottom histogram (darkened for contrast) in each column shows $\log |r|$, plotted on the same length of axis (13 orders of magnitude) to enable visual comparison of the distributions of $\log \left|J /\left(\mathrm{A} / \mathrm{cm}^{2}\right)\right|$ and $\log |r|$. All histograms have been fitted with Gaussians (black lines), and the means and standard deviations determined from these Gaussians are shown above each histogram. 

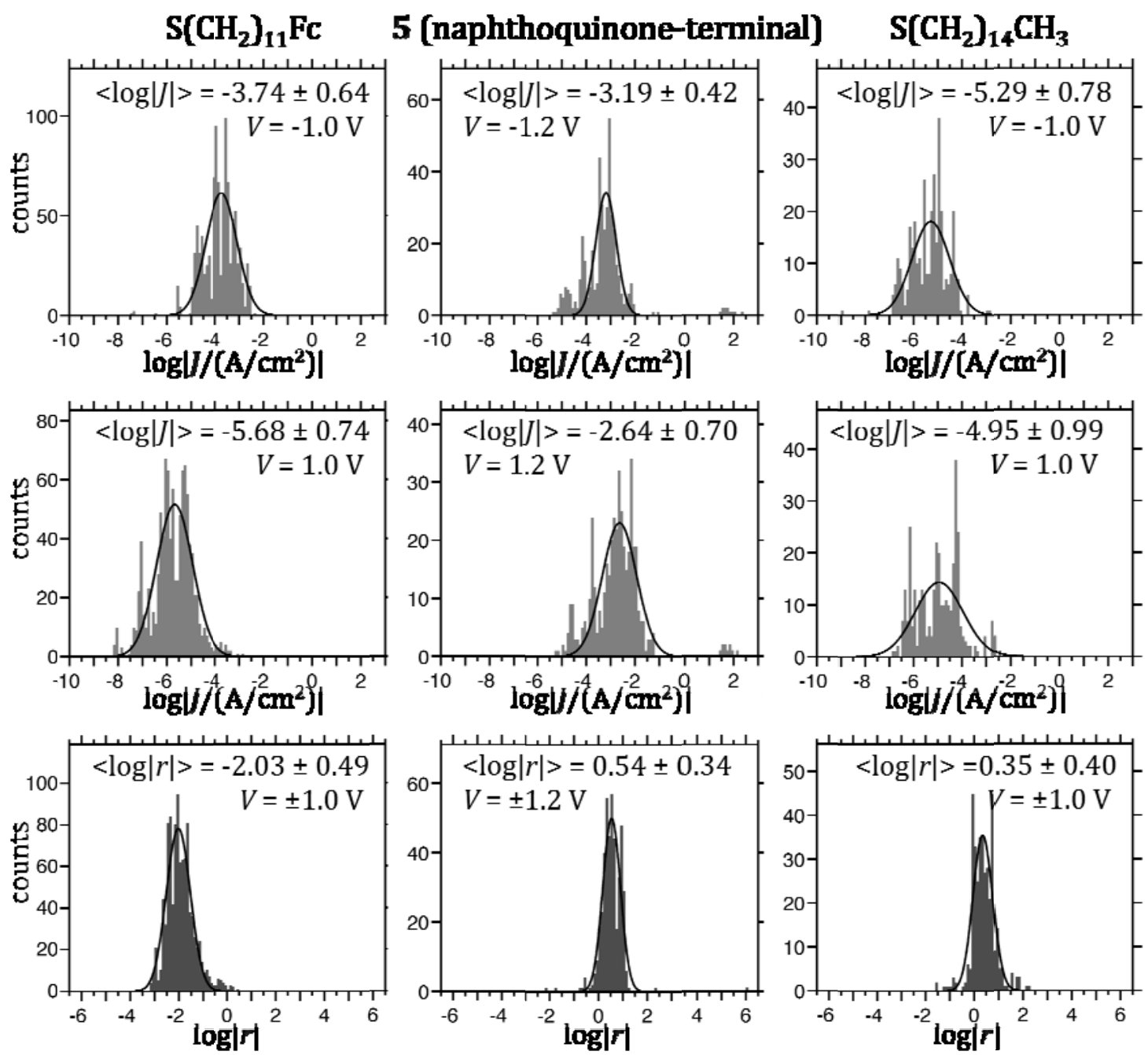

Figure 7 
The $x$-axes of all histograms span the same width on a log-scale: 13 orders of magnitude. Comparing histograms of the two quantities, we observe that i) the variance (square of the standard deviation) of $\log |r|$ is typically less than or equal to the variance of $\log \left|J /\left(\mathrm{A} / \mathrm{cm}^{2}\right)\right|$, and ii) histograms of $\log |r|$ are less noisy and have fewer outliers (virtually none, in fact) than histograms of $\log \left|J /\left(\mathrm{A} / \mathrm{cm}^{2}\right)\right|$. These observations are valid for the other compounds investigated in this paper, and they confirm the advantages of using rectification to study charge transport in SAMs. Values of $\log |r|$ represent the difference between values of $\log |J(1.0 \mathrm{~V})|$ and $\log |J(-1.0 \mathrm{~V})|$. Ordinarily, when a variable $X$ is the difference between variables $A$ and $B$, the variance of $X$ is greater than the variances of both $A$ and $B$, assuming $A$ and $B$ are independent. When $A$ and $B$ are not independent, however, the variance of $X$ can actually be less than the variances of $A$ and $B$ separately (in statistical terms, this decrease in variance occurs because the covariance of $A$ and $B$ is large). Because $\log |J(1.0 \mathrm{~V})|$ and $\log |J(-1.0 \mathrm{~V})|$ are measured across the same junction, they are highly correlated (i.e. they have a large covariance). The fact that $\log |r|$ is a selfreferencing measurement, therefore, explains why the error in $\log |r|$ is typically less than the error in $\log |J|$, as seen in Figure 7.

\section{Discussion}

In this section, we use the evidence introduced above in the "Background" and "Results" sections, in order to evaluate the mechanism of rectification we propose against alternative mechanisms. The first subsection discusses our mechanism, while each subsequent subsection is devoted to one alternative mechanism. 
Our Proposed Mechanism: Asymmetric Placement of a Conducting Molecular Orbital within a Tunneling Junction Allows the Orbital to Participate in Redox Reactions at One Bias, but not the Opposite Bias.

This mechanism is supported by a number of predictions borne out by experimental evidence, which we have reviewed in the "Background" section. In summary, our proposed mechanism of rectification - the asymmetric coupling of a molecular orbital to one electrode causing the orbital to participate in charge transport at one bias, but not the opposite bias - explains the signs and relative magnitudes of the values of $R$ observed for $\mathrm{S}\left(\mathrm{CH}_{2}\right)_{9} \mathrm{Fc}, \mathrm{S}\left(\mathrm{CH}_{2}\right)_{11} \mathrm{Fc}$, and $\mathrm{S}\left(\mathrm{CH}_{2}\right)_{11} \mathrm{Fc}_{2}$. This mechanism finds further validation through temperature-dependent studies of $\mathrm{S}\left(\mathrm{CH}_{2}\right)_{11} \mathrm{Fc}$ that show hopping (between the $\mathrm{Fc}$ moiety and the $\mathrm{Ga}_{2} \mathrm{O}_{3} /$ EGaIn electrode) at negative bias, but not at positive bias. ${ }^{24}$ These data, collectively, are also incompatible - in our view - with mechanisms for rectification that depend on the properties of the metals in the electrodes (e.g. Fermi levels) or of the oxide skin (e.g. redox reactions); we elaborate these points in the following subsections.

\section{Other Hypotheses}

We evaluate alternative mechanisms of rectification using the following format: i) a summary of the mechanism in question, ii) a discussion of the evidence for or against it, iii) our conclusion concerning the compatibility of the mechanism in question with the experimental data. 
Hypothesis: Rectification is the result of asymmetries due to electrodes with different work functions, or to the presence of one chemisorbed contact (Ag-S) and one van der Waals contact (SAM//Ga $\left.a_{2} \mathrm{O}_{3} / E G a I n\right)$.

Summary: EGaIn and Ag have bulk work functions that are slightly different $(\mathrm{Ag} \approx-4.5 \mathrm{eV}, \mathrm{EGaIn} \approx-4.2 \mathrm{eV}),{ }^{19}$ but the actual work functions at the surfaces of the $\mathrm{Ag}^{\mathrm{TS}}$ and $\mathrm{Ga}_{2} \mathrm{O}_{3} / \mathrm{EGaIn}$ electrodes, in the environment of the $\mathrm{Ag}^{\mathrm{TS}}{ }_{-} \mathrm{SAM} / / \mathrm{Ga}_{2} \mathrm{O}_{3} / \mathrm{EGaIn}$, may differ from the bulk values. The fact that we must use a potential range of $V=-1.2$ $\mathrm{V}$ to $1.2 \mathrm{~V}$ when measuring compounds $\mathbf{2}$ and $\mathbf{5}$ may be evidence that the work functions of the electrodes differ (see the "Results" section). For example, if the actual work function of the $\mathrm{Ag}^{\mathrm{TS}}$ electrode is indeed $0.3 \mathrm{eV}$ greater (i.e. if the Fermi energy ${ }^{48}$ of $^{\mathrm{Ag}^{\mathrm{TS}}}$ electrode is $0.3 \mathrm{eV}$ lower) than that of the $\mathrm{Ga}_{2} \mathrm{O}_{3} / \mathrm{EGaIn}$ electrode, then this difference in work functions causes the tunneling barrier posed by the SAM to change from an approximately flat (rectangular) barrier to a tilted (trapezoidal) barrier, sloping downward towards the $\mathrm{Ga}_{2} \mathrm{O}_{3} / \mathrm{EGaIn}$ electrode. The shape of the tunneling barrier would, therefore, be asymmetric, and electrons (or holes) approaching the barrier from opposite sides would tunnel at different rates. ${ }^{49}$ In this way, the value of $J$ at one applied bias would differ from that at the opposite applied bias. In addition, the asymmetry of having a chemisorbed contact and a van der Waals contact at opposite ends of the junction almost certainly would increase this asymmetry in the shape of the tunneling barrier and, in the same way, might cause rectification. In tunneling diodes, an inorganic insulator is sandwiched between two different metals, and the difference between the work functions of the metals causes rectification. Even in commercial tunneling diodes, it is a challenge to achieve values of $R>6 .^{50}$ 
Evidence against: While we do believe that one or both of these mechanisms (perhaps combined with others) results in the slight rectification $(R=1.5-3.5)$ observed for a variety of SAMs, several control experiments rule out this mechanism as an explanation for the large rectification $(R(1.0 \mathrm{~V})=-100)$ observed with Fc-terminated SAMs.

i) As mentioned previously and depicted in Figure 1E and F, SAMs of n-alkanethiols, lacking a conductive molecular orbital, show rectification ratios different from that of $\mathrm{S}\left(\mathrm{CH}_{2}\right)_{11} \mathrm{Fc}(R=-100)$ by more than two orders of magnitude. For SAMs of $\mathrm{S}\left(\mathrm{CH}_{2}\right)_{10} \mathrm{CH}_{3}, R(1.0 \mathrm{~V})=1.5$, whereas $R(1.0 \mathrm{~V})=2.3$ for $\mathrm{SAMs}$ of $\left.\mathrm{S}_{\left(\mathrm{CH}_{2}\right)}\right)_{14} \mathrm{CH}_{3}$. We note, in addition, that values of $R$ for n-alkanethiols have the opposite sign to that of $\mathrm{S}\left(\mathrm{CH}_{2}\right)_{11} \mathrm{Fc}$-i.e., $|J|$ is higher at positive bias than at negative bias for n-alkanethiols, and vice versa for $\mathrm{S}\left(\mathrm{CH}_{2}\right)_{11} \mathrm{Fc}$. This result is difficult to explain using only the asymmetry of the electrodes. Asymmetry in the electrodes and/or the interfaces may cause the slight rectification observed for n-alkanethiols, but not the large rectification observed for Fcterminated SAMs, and not the change in the bias at which rectification occurs.

ii) In addition to these two alkanethiols, we have also previously reported ${ }^{21}$ measurements of a complete series of n-alkanethiols $(n=9-18)$ within a bias range of $V$ $= \pm 0.5 \mathrm{~V}$. If a difference between the work functions of the electrodes were to cause significant rectification at $\pm 1.0 \mathrm{~V}$, then this effect would also be evident at $\pm 0.5 \mathrm{~V}$ (although smaller than at $\pm 1.0 \mathrm{~V}$ ). ${ }^{49}$ For these ten alkanethiolates, we observed a range of values of $R(0.5 \mathrm{~V})$ from $1.1-2.2$. These values match the values of $R(1.0 \mathrm{~V})$ reported here for $\mathrm{S}\left(\mathrm{CH}_{2}\right)_{10} \mathrm{CH}_{3}$ and $\mathrm{S}\left(\mathrm{CH}_{2}\right)_{14} \mathrm{CH}_{3}$, and strengthen the claim that the values of $R$ observed for alkanethiolates are, indeed, much smaller than those observed for the three 
Fc-based molecular diodes discussed in this work. Again, this result is difficult to explain using only the difference between the electrodes.

iii) Also mentioned previously, SAMs with the $\mathrm{Fc}$ in the middle of the alkyl chain, $\mathrm{S}\left(\mathrm{CH}_{2}\right)_{6} \mathrm{Fc}\left(\mathrm{CH}_{2}\right)_{5} \mathrm{CH}_{3}$ (Figure 2B) are not molecular diodes $(R(1.0 \mathrm{~V})=1.2)$. Changing the position of the $\mathrm{Fc}$ moiety probably does not change the work functions of the electrodes. While the position of the Fc moiety does affect the interface between the SAM and the electrodes, the difference in $R$ between, say, $\mathrm{S}\left(\mathrm{CH}_{2}\right)_{6} \mathrm{Fc}\left(\mathrm{CH}_{2}\right)_{5} \mathrm{CH}_{3}$ and $\mathrm{S}\left(\mathrm{CH}_{2}\right)_{11} \mathrm{Fc}$ is too large to be explained simply by a change in the shape of the tunneling barrier, since an asymmetric tunneling barrier can only produce $R<6 .{ }^{50}$

Conclusion: If electrodes having different Fermi levels, or having different contacts (chemisorbed versus van der Waals) with the SAM, were sufficient to cause the rectification $(R=-100)$ observed with SAMs of $\mathrm{S}\left(\mathrm{CH}_{2}\right)_{11} \mathrm{Fc}$, then one would expect to see the same magnitude of rectification for any SAM in the junction, including simple nalkanethiol SAMs, and SAMs having the Fc moiety in the middle. Since we do not observe significant rectification in these cases, we conclude that mechanisms based on asymmetry in the Fermi levels of the contact electrodes are not sufficient to explain either the magnitude or the sign of the observed rectification.

Hypothesis: Embedded dipoles in the SAM give the tunneling barrier an asymmetric shape

Summary: Attaching functional groups to the end of the SAM (or incorporating them into the alkyl chain of the SAM) can change the dipole moment within the junction. A dipole present in a tunneling junction induces an electrical field, which causes the 
tunneling barrier to tilt towards one electrode or the other and produces a tunneling barrier with an asymmetric shape. Either of these effects could result in rectification.

Evidence against: i) As described in the "Results" section, we measured junctions incorporating SAMs of $\mathrm{S}\left(\mathrm{CH}_{2}\right)_{10} \mathrm{CH}_{2} \mathrm{OH}$ and $\mathrm{S}\left(\mathrm{CH}_{2}\right)_{10} \mathrm{COOH}$ (11-mercaptoundecanoic acid), both of which present polar functional groups at the surface of the SAM. Figure $5 \mathrm{~B}$ and $5 \mathrm{C}$ show that these SAMs have small values of $R: \mathrm{S}_{\left(\mathrm{CH}_{2}\right)}{ }_{10} \mathrm{CH}_{2} \mathrm{OH}$ gives $R(1.0$ $\mathrm{V})=2.5(<\log |r|>=0.40 \pm 0.32)$ and $\mathrm{S}\left(\mathrm{CH}_{2}\right)_{10} \mathrm{COOH}$ yields $R(1.0 \mathrm{~V})=2.4(<\log |r|>=$ $0.38 \pm 0.25)$. The multiple comparison test described in the "Results" section confirms that these compounds are not molecular diodes - their values of $R$ are not statistically distinguishable from those of alkanethiols. These observations indicate that changing the dipole of the SAM from that of an alkanethiol to that of a hydroxyl- or carboxylic acidterminated alkanethiol changes $R$ by less than a factor of 2. The dipole of the SAM, therefore, has only a minimal effect on rectification.

ii) We have synthesized and measured several compounds containing secondary amide groups in the middle of the alkyl chain (these new results will be described in detail in forthcoming publications). SAMs of these molecules should have a significant internal dipole, and while we have only measured these SAMs over a potential window of $V= \pm 0.5 \mathrm{~V}$, we have not observed values of $R$ significantly different from those of alkanethiols. The highest value of $R$ that we observed was $R(0.5 \mathrm{~V})=1.6(\log |r|=0.20 \pm$ 0.20), for $\mathrm{S}\left(\mathrm{CH}_{2}\right)_{10} \mathrm{CONHCH}_{3}$.

Conclusion: Several SAMs with dipoles in the interior and at the surface of the SAM do not rectify appreciably. We conclude that a molecular dipole is not sufficient to cause 
the rectification we observe for SAMs of $\mathrm{S}\left(\mathrm{CH}_{2}\right)_{11} \mathrm{Fc}$ (this conclusion does not preclude the possibility that a molecular dipole in another SAM might cause rectification).

Hypothesis: Redox processes within the metal oxide film might occur at one bias, but not the opposite bias

Summary: The oxide film on EGaIn is primarily $\mathrm{Ga}_{2} \mathrm{O}_{3}$, with small amounts of other oxides of gallium and indium. Possible redox reactions within the oxide film (for example, $\mathrm{Ga}^{3+}+2 \mathrm{e}^{-} \rightarrow \mathrm{Ga}^{+}$, etc.) would be analogous to those in Table $\mathrm{S} 1$ (see Supporting Information) involving $\mathrm{Ga}$ and $\mathrm{In}$ in aqueous solution. The reduction potentials for reactions within the oxide film would not necessarily be the same as those for reactions in solution; nevertheless, we can make a qualitative comparison between the two. The $\mathrm{Ga}^{3+}$ in $\mathrm{Ga}_{2} \mathrm{O}_{3}$ is probably easier to reduce than $\mathrm{Cr}^{3+}$ in $\mathrm{Cr}_{2} \mathrm{O}_{3}$, and more difficult to reduce than $\mathrm{Ni}^{2+}$ in $\mathrm{NiO}$. The aqueous reactions in Table $\mathrm{S} 1$ involving Ga and In have negative reduction potentials; the analogous reactions in the oxide film are, therefore, most probable when the EGaIn is biased negatively (reducing conditions) with a magnitude greater than the reduction potential of a particular redox couple. Since the half reaction of $\mathrm{Ga}^{3+}+3 \mathrm{e}^{-} \rightleftarrows \mathrm{Ga}$, for example, would occur at negative bias $\left(V \leq E^{\circ}, E^{\circ}=\right.$ $-0.549 \mathrm{~V}$ ) but not positive bias, it might enhance the flow of electrons at negative bias and, thus, result in rectification. It is not clear how this hypothesis would account for rectification (we detail a more plausible hypothesis, involving redox reactions in both the $\mathrm{Ga}_{2} \mathrm{O}_{3}$ film and the SAM, in the next section). If the $\mathrm{Ga}^{3+}$ in the $\mathrm{Ga}_{2} \mathrm{O}_{3}$ film were to be reduced at negative bias by some finite current, then there is no apparent reason why it could not be oxidized again at positive bias by an equivalent current in the opposite 
direction; this mechanism would thereby produce no rectification. Due to the uncertainty associated with the $\mathrm{Ga}_{2} \mathrm{O}_{3}$ film, however, and out of a desire to put to rest any doubts about its influence on charge transport in our junctions, we still take this hypothesis seriously and choose to rebut it on evidential grounds, rather than using only a priori arguments.

Evidence against: i) SAMs of n-alkanethiols do not exhibit substantial rectification $\left(R=1.5\right.$ and 2.3, Figure 1E and F), nor do those with polar head groups $\left(\mathrm{CH}_{2} \mathrm{OH}\right.$ and COOH: $R=2.5$ and 2.4, respectively; Figure 5). These observations imply that these redox reactions either do not occur for SAMs that are not molecular diodes, or are not, by themselves, significant enough to explain the magnitude rectification in the molecular diodes reported here.

ii) According to the multiple comparison test described in the "Results" section, SAMs of $\mathrm{S}\left(\mathrm{CH}_{2}\right)_{6} \mathrm{Fc}\left(\mathrm{CH}_{2}\right)_{5} \mathrm{CH}_{3}$, with the $\mathrm{Fc}$ in the middle of the SAM, do not qualify as molecular diodes ( $R=1.2$, Figure 1D). This observation establishes that the presence of a redox active moiety, by itself, in the SAM, coupled with the possible redox reactions in the metal oxide film, is not sufficient to cause the rectification observed with Fcterminated SAMs.

iii) In the supporting information of our original publication ${ }^{23}$ showing rectification with SAMs of $\mathrm{S}\left(\mathrm{CH}_{2}\right)_{11} \mathrm{Fc}$, we reported measurements of SAMs of $\mathrm{S}\left(\mathrm{CH}_{2}\right)_{11} \mathrm{Fc}$ on $\mathrm{Ag}^{\mathrm{TS}}$ using a $500 \mathrm{~nm}$-thick $\mathrm{Au}$ foil as a top-electrode $\left(\mathrm{Ag}^{\mathrm{TS}}-\mathrm{S}\left(\mathrm{CH}_{2}\right)_{11} \mathrm{Fc} / / \mathrm{Au}\right.$ junctions $)$. While this experiment was technically demanding and did not generate enough data for statistical analysis, we were able to fabricate five working junctions, in which we observed rectification ratios, $R(1.0 \mathrm{~V}) \approx-10--100$, with the same sign, and similar 
magnitude, as the values of $R$ observed using $\mathrm{Ga}_{2} \mathrm{O}_{3} /$ EGaIn electrodes; rectification in these junctions certainly occurred in the absence of any metal oxide film.

v) The group of Zandvliet et al. ${ }^{51}$ reported that junctions of form of Au$\mathrm{S}\left(\mathrm{CH}_{2}\right)_{11} \mathrm{Fc}$-(vacuum)-Pt/Ir (the top-electrode is an STM tip) also rectify currents, with $R(2.0 \mathrm{~V}) \approx-10$. In these measurements, the substrate was biased and the tip was grounded, so although they report that $J(+2.0 \mathrm{~V})$ was greater than $J(-2.0 \mathrm{~V})$, according to the convention used in this paper (i.e. treating the electrode bound to the thiol as ground), $J(-2.0 \mathrm{~V})$ is greater than $J(2.0 \mathrm{~V})$, and $R$ has a negative sign. In short, the junctions incorporating $\mathrm{S}\left(\mathrm{CH}_{2}\right)_{11} \mathrm{Fc}$ measured by Zandvliet et al. did not have any oxidizable components, yet these junctions still gave negative values of $R$, as did our junctions. Redox processes in the $\mathrm{Ga}_{2} \mathrm{O}_{3}$ film, if they do indeed occur, cannot be entirely responsible for the rectification we observe in our molecular diodes. The fact that the values of $R$ reported by Zandvliet et al. are roughly a factor of ten lower than what we observe for the same molecule is explained by our proposed mechanism: the vacuum gap in their junctions decreases the necessary asymmetry of their junctions, relative to our junctions. In our junctions, the $\mathrm{Fc}$ moiety is in direct contact with the $\mathrm{Ga}_{2} \mathrm{O}_{3} / \mathrm{EGaIn}$ electrode. We have shown that electrons can, in fact, hop between the Fc group and the electrode; this mechanism significantly enhances the rate charge transport at negative bias over that at positive bias. The junctions of Zandvliet et al. cannot take advantage of hopping between the Fc moiety and the Pt/Ir STM tip, because the vacuum gap between the tip and the SAM prevents it.

Conclusion: Because, in the set of SAMs we have observed, only some SAMs with redox-active groups (and not even with all of them) are molecular diodes, because 
different SAMs cause rectification to switch polarity entirely, because the magnitude of the rectification ratio appears to correlate with the energy of the accessible molecular orbital, and because we and others have demonstrated rectification from the same molecule in the absence of a metal oxide film, we conclude that the observed rectification cannot be due to redox processes in the metal oxide film. Although these intra-film redox reactions may occur, they are not sufficient to account for our results—in fact, there is no evidence that they cause any rectification in $\mathrm{Ag}^{\mathrm{TS}}-\mathrm{SAM} / / \mathrm{Ga}_{2} \mathrm{O}_{3} / \mathrm{EGaIn}$ junctions. We conclude that the structure of the SAM, not the redox behavior of the $\mathrm{Ga}_{2} \mathrm{O}_{3}$ surface film, determines the sign and magnitude of $R$ in our junctions.

Hypothesis: Electrochemical reactions that require both a redox-active SAM and the $\mathrm{Ga}_{2} \mathrm{O}_{3}$ film might occur at one bias, but not the opposite bias

Summary: This mechanism would be similar to the previous one involving redox processes occurring inside the $\mathrm{Ga}_{2} \mathrm{O}_{3}$ film, except that the previous mechanism asserts that the $\mathrm{Ga}_{2} \mathrm{O}_{3}$ film is sufficient for rectification, while this mechanism asserts that the $\mathrm{Ga}_{2} \mathrm{O}_{3}$ film is necessary, but not sufficient, for rectification. In other words, this mechanism posits that the reaction of a redox-active $\mathrm{Ga}_{2} \mathrm{O}_{3}$ film with a redox-active SAM is responsible for rectification. This mechanism is close to our proposed mechanism of rectification in $\mathrm{SAMs}$ of $\mathrm{S}\left(\mathrm{CH}_{2}\right)_{11} \mathrm{Fc}$ : in both mechanisms, the $\mathrm{Fc}$ moiety at the $\mathrm{SAM} / / \mathrm{Ga}_{2} \mathrm{O}_{3}$ interface undergoes a redox reaction, The question, however, is whether this reaction couples with another redox reaction in the metal oxide layer (as in this hypothesis) or not (as in the mechanism we defend in this work). 
Wrighton et al. ${ }^{26}$ have demonstrated rectification in a micron-scale electrochemical junction between two redox-active polymers, one of which contained Fc groups. The mechanism of rectification in these junctions involves two redox reactions that couple in a specific order-i.e. electrons flow from the first redox couple to the second, but not in the opposite direction — resulting in the flow of current at one bias, but not the opposite bias. It is important to note that these junctions were assembled and tested in a wet electrochemical environment in the presence of a reference electrode (saturated calomel). Also, compared to SAM-based junctions (in which the electrodes are separated by $1-2$ $\mathrm{nm})$ these polymer-based junctions are large ( $\sim 1 \mu \mathrm{m}$ between electrodes), and charge transport through them cannot involve tunneling.

Evidence against: i) Junctions of the form $\mathrm{Ag}^{\mathrm{TS}}-\mathrm{S}\left(\mathrm{CH}_{2}\right)_{11} \mathrm{Fc} / / \mathrm{Au}$, with top-electrodes of Au foil (Supporting Information of ref. 23), rectify with approximately the same value of $R(R(1.0 \mathrm{~V})=-100)$ as $\mathrm{Ag}^{\mathrm{TS}}-\mathrm{S}\left(\mathrm{CH}_{2}\right)_{11} \mathrm{Fc} / / \mathrm{Ga}_{2} \mathrm{O}_{3} / \mathrm{EGaIn}$ junctions, even without a metal oxide film. The metal oxide film is, therefore, not a necessary condition for rectification.

ii) The results of Zandvliet et al., ${ }^{51}$ in which $\mathrm{Au}-\mathrm{S}\left(\mathrm{CH}_{2}\right)_{11} \mathrm{Fc}$-(vacuum)-Pt/Ir junctions give $R(2.0 \mathrm{~V}) \approx-10$, show that a redox-active top-electrode is not necessary for rectification. In these junctions, as in ours, a Fc group located asymmetrically within the SAM is sufficient for rectification.

Conclusion: We conclude that rectification in SAMs of $\mathrm{S}\left(\mathrm{CH}_{2}\right)_{11} \mathrm{Fc}$ is the result of a redox reaction involving the $\mathrm{Fc}$ moiety. We further conclude that the evidence rules out the participation of the metal oxide film in this redox reaction (or at least demonstrates that it does not contribute appreciably to rectification). 
Hypothesis: Depletion of charge carriers from the metal oxide creates a rectifying Schottky barrier

Summary: The layer of $\mathrm{Ga}_{2} \mathrm{O}_{3}$ is semiconducting and might have a significant concentration of free charge carriers arising from interface states, non-stoichiometric regions, oxygen vacancies or excesses, etc. ${ }^{52}$ Since this layer is adjacent to a bulk metal alloy (EGaIn) and a SAM containing an electron donor $(\mathrm{Fc})$, these charge carriers might become depleted and form a Schottky barrier; generation of a Schottky barrier could lead to rectification (as in Schottky diodes).

Evidence against: i) $R$ switches sign when the Fc HOMO is replaced by a non-polar, polar, or aromatic group. Therefore, if depletion of charge in the $\mathrm{Ga}_{2} \mathrm{O}_{3}$ occurs, it is due to the redox-active moiety in the SAM, and not the bulk EGaIn (which would produce a constant effect for all SAMs). Not all SAMs with a redox-active moiety qualify as molecular diodes, however: as examples $\mathrm{S}\left(\mathrm{CH}_{2}\right)_{6} \mathrm{Fc}\left(\mathrm{CH}_{2}\right)_{5} \mathrm{CH}_{3}$, with $\mathrm{Fc}$ buried in the SAM, gives $R=1.2$ and compounds 2 (with trimethylbenzoquinone at the unbound surface of the SAM) gives $R=1.9$. These rectification ratios are comparable to those derived from n-alkanethiolate SAMs or other molecules not having accessible frontier orbitals. Therefore, doping or depletion is either strongly dependent on the molecular structure of the SAM, or not involved in rectification.

ii) If a layer of oxide has significant free charge carriers, then it must be either n-type or p-type, but it cannot be both. An electron donor, such as the HOMO of Fc, can only deplete a p-type semiconductor, not an n-type semiconductor, in order to form a Schottky barrier. $\mathrm{Ga}_{2} \mathrm{O}_{3}$ grown under oxidizing conditions is an insulator (i.e. it is neither n-type 
nor p-type), and although common defects in $\mathrm{Ga}_{2} \mathrm{O}_{3}$ can cause the material to become an n-type semiconductor, $\mathrm{p}$-type $\mathrm{Ga}_{2} \mathrm{O}_{3}$ does not form under ambient conditions. ${ }^{53,54}$ It is, therefore, unlikely that the $\mathrm{Ga}_{2} \mathrm{O}_{3}$ film would be the type of semiconductor that is able to form a Schottky barrier in the presence of Fc.

iii) Finally, we have estimated the average thickness of the layer of oxides, using angle-resolved X-ray photoelectron spectroscopy, as $\sim 0.7 \mathrm{~nm}^{18}$ (this value is consistent with that reported by Regan et al.). ${ }^{17}$ In all but the most highly doped semiconductors, the formation of a depletion region requires a layer of material several microns thick. Without sufficient material to form a depletion layer, it is impossible to form a Schottky barrier.

Conclusion: Because of the ability to control the polarity of rectification using the SAM, and because the layer of oxides is too thin to form a depletion layer, we conclude that the observed rectification is not the result of a Schottky barrier.

Hypothesis: Doping of the metal oxide leads to different resistivities at opposite bias and causes rectification.

Summary: For some oxides (e.g. $\mathrm{TiO}_{2}$ ), it is possible to dope the oxide with mobile ions or defects that migrate in response to an applied electric field. Such a modification leads to a memristor ${ }^{25}$ - a resistor whose resistance changes in response to an applied electric field (i.e. a resistor with a memory). While memristors do not necessarily rectify, one could imagine how the migration of ions or defects might be more favorable in one direction than the other, and that this effect might be controlled or enhanced by a SAM. 
This effect would lead to a difference between the resistance at positive and negative bias and, hence, rectification.

Evidence against: i) If this effect occurs, then the dopants are probably either oxygen vacancies or excess interstitial oxide ions; doping is, therefore, probably strongly dependent on the oxygen content of the environment in which the junctions are measured. In a previous paper, ${ }^{24}$ we reported temperature-dependent measurements of junctions containing SAMs of $\mathrm{S}\left(\mathrm{CH}_{2}\right)_{11} \mathrm{Fc}$. These measurements were carried out under high vacuum $\left(10^{-6} \mathrm{bar}\right)$; we observed no change in the rectification ratio, relative to the measurements carried out at ambient pressure $(R=-100$ for both conditions with the $\mathrm{Fc}$ terminated SAMs). Since dramatically changing the oxygen content of the atmosphere did not change the value of $R$, it is unlikely that adventitious dopants in the $\mathrm{Ga}_{2} \mathrm{O}_{3}$ film are responsible for rectification.

ii) If placing a redox-active moiety at the surface of the SAM can cause rectification by affecting the migration of dopants, then placing a dipole at the surface of the SAM, or a redox-active moiety in the center of the SAM, might also cause rectification. SAMs of $\mathrm{S}\left(\mathrm{CH}_{2}\right)_{10} \mathrm{CH}_{2} \mathrm{OH}, \mathrm{S}\left(\mathrm{CH}_{2}\right)_{10} \mathrm{COOH}$, and $\mathrm{S}\left(\mathrm{CH}_{2}\right)_{6} \mathrm{Fc}\left(\mathrm{CH}_{2}\right)_{5} \mathrm{CH}_{3}$ (Table 1, Figure $5 \mathrm{~B}$ and $\mathrm{C}$, and Figure 1D) do not, however, exhibit rectification significantly different from that of alkanethiols, and do not, therefore, qualify as molecular diodes.

Observations Possibly Related to this Mechanism: Memristors exhibit hysteresis in plots of current vs. voltage. We do see a slight hysteresis in the $J(\mathrm{~V})$ traces of junctions containing SAMs of $\mathrm{S}\left(\mathrm{CH}_{2}\right)_{11} \mathrm{Fc}$, but it is only apparent close to zero bias. Furthermore, we do not observe this hysteresis with naphthoquinone-terminated SAMs (compound 5), which are also molecular diodes. 
Velders et al., ${ }^{55}$ in collaboration with us, did see a hysteresis in the $J(\mathrm{~V})$ traces of junctions containing monolayers of Fc-terminated dendrimers adsorbed on SAMs presenting a surface of cyclodextrins. These junctions are stable at biases up to $\pm 3.0 \mathrm{~V}$ (because these monolayers are about $7 \mathrm{~nm}$ thick and, therefore, experience weaker electric fields than thinner monolayers), and while their $J(V)$ characteristics do significantly change upon prolonged measurement at $\pm 3.0 \mathrm{~V}$, they show no change when measured at biases less than $\pm 2.0 \mathrm{~V}$. These dendrimers, however, are chemically very different from the present SAMs: they contained water complexed to the cyclodextrins and to the amines near the core of the dendrimers (these protonated amines also have $\mathrm{Cl}^{-}$ as counter ions). We did not see changes in the $J(V)$ characteristics of junctions containing $\mathrm{S}\left(\mathrm{CH}_{2}\right)_{11} \mathrm{Fc}$, or any of the SAMs mentioned here, at any voltage applied during our experiments. Junctions containing $\mathrm{S}\left(\mathrm{CH}_{2}\right)_{11} \mathrm{Fc}$ tended to short in the range of $\sim \pm 1.5 \mathrm{~V}$, so we could not test the possibility that applying a large bias across the junction dopes the $\mathrm{Ga}_{2} \mathrm{O}_{3}$ film and causes it to function as a memristor. While applying biases of $\pm 3.0 \mathrm{~V}$ causes a large, irreversible change to the $J(\mathrm{~V})$ characteristics of some junctions, these biases are well outside of the range of biases that we apply to our junctions. If, on the other hand, the $\mathrm{Ga}_{2} \mathrm{O}_{3}$ behaving as a memristor at low bias $(-1.0 \mathrm{~V} \leq \mathrm{V} \leq 1.0 \mathrm{~V})$ is responsible for the small hysteresis in the $J(\mathrm{~V})$ traces of $\mathrm{S}\left(\mathrm{CH}_{2}\right)_{11} \mathrm{Fc}$, then this effect is so small that it cannot be the cause of the large values of $R$ that we observe.

Conclusion: Based on measurements in high vacuum, and other controls, we conclude that, while we cannot completely exclude the effects of variable or mobile dopants in the metal oxide, this phenomenon is not responsible for the rectification that we observe. 


\section{Conclusions}

\section{Rectification and charge transport in $\mathrm{Ag}^{\mathrm{TS}}$-SAM//Ga $\mathrm{O}_{3} / E$ EaIn junctions are}

determined by the SAM. Because charge transport in organic matter is still incompletely understood, we believe that claims of molecular rectification — or any claim related to molecular charge transport, for that matter-must be carefully examined, in order to rule out non-molecular mechanisms involving metals, metal oxides, or other components of the system (organic adsorbates, atmospheric gases). While our junctions employ a topelectrode with a metal (EGaIn) whose surface oxidizes spontaneously to a $\mathrm{Ga}_{2} \mathrm{O}_{3}$ film on contact with air, and while this $\mathrm{Ga}_{2} \mathrm{O}_{3} / \mathrm{EGaIn}$ electrode might have a different work function than the $\mathrm{Ag}^{\mathrm{TS}}$ bottom-electrode, this fact does not disqualify our junctions, $a$ priori, from use in measuring charge transport through SAMs; it simply places the burden of proof on us to show that the results generated using these junctions are truly molecular, and not dominated by the electrodes.

This paper considers an exhaustive list of alternative mechanisms related to asymmetric and/or oxidizable electrodes, in light of experiments (both published and new) that test these alternative mechanisms by changing the structure of the SAM. From these results, we conclude that mechanisms involving the $\mathrm{Ga}_{2} \mathrm{O}_{3}$ film, or the asymmetry of the electrodes, are insufficient to explain the large values of $R$ for our molecular diodes, or the dependence of both the magnitude and sign of $R$ on molecular structure. The value of $R$ is, essentially, a self-referencing measurement of charge transport. Because $R$ is sensitive to the SAM and not determined by the other components of the 
junction, charge transport through these junctions, therefore, reflects the structure and properties of the SAM, not the electrodes or the $\mathrm{Ga}_{2} \mathrm{O}_{3}$ film.

One accessible molecular orbital located asymmetrically between two electrodes is sufficient for rectification. We are also convinced that, of the several possible mechanisms in which rectification has a molecular origin, the only one that fits our results posits that rectification occurs as the result of the asymmetric placement inside the junction of an accessible molecular orbital. The donor-bridge-acceptor structure of the molecular diode proposed by Aviram and Ratner $^{1}$ and realized by others ${ }^{27,28,29,30,31,32}$ is, therefore, not required for rectification (contrary to the claims of Ashwell, et. al. ${ }^{12}$ ). While the donor-bridge-acceptor has been shown to rectify, no study has conclusively identified the mechanism of rectification, so it is unclear whether this structure is sufficient for rectification. We note that, in many studies of molecules of this sort, the donor and acceptor moieties were significantly offset from the center of the junction (closer to one electrode than the other). Since both moieties are potentially accessible molecular orbitals, it is possible that some of these junctions rectify due to the asymmetric placement of a molecular orbital(s) between the electrodes. Such an explanation needs to be ruled out before the community can conclude that, for a given molecule in a given type of junction, the donor-bridge-acceptor structure alone, and not any other asymmetry, is responsible for rectification.

$R$ is statistically significant. Statistical tests demonstrate the significance of the values of $R$ for the three ferrocene-based molecular diodes discussed here, when compared to those of alkanethiolate SAMs, and indicate (together with the other evidence discussed in this paper) that rectification in these diodes has a molecular origin. The 
largest of our values of $R$ comes from $\mathrm{S}\left(\mathrm{CH}_{2}\right)_{11} \mathrm{Fc}_{2}$, for which $R=-500$. While individual values of $|R|$ greater than 500 have been reported in the literature (e.g. $R=3000$ by

Ashwell et al. ${ }^{32}$ ), our value of $R$ is the log-average of an entire distribution of hundreds of discretely observed rectification ratios. Most publications on molecular rectification simply report individual values, without any statistical analysis of the distribution of observed values. If we followed the same procedure, we could claim the highest rectification ratio from a molecular rectifier to date: in the histogram of $\log |r|$ for our best rectifier, $\mathrm{S}\left(\mathrm{CH}_{2}\right)_{11} \mathrm{Fc}_{2}, \sim 20 \%$ of the measured values of $\log |r|$ are in the range of $-3--4$ (i.e. $R=-1000--10,000$ ), with a few values approaching -5 (e.g. $R=-100,000$; Figure 3A). We know that these high individual values are, however, outliers and may be artifacts or errors, and reporting them would obscure the fact that they are different, to a suspicious degree, from the average value, $<\log |r|>$. Examining the entire distribution of $\log |r|$ and reporting the average, while less impressive than reporting single values, enables the identification of these extreme values as outliers, and affords a representative and meaningful characterization of the results.

\section{Acknowledgements}

This research was supported by the U.S. Department of Energy, under Award \# DESC0000989 (synthesis of materials, partial support for measurements of charge transport, and support for W.F.R.), and by the National Science Foundation under Awards \# CHE05180055 (partial support for measurements of charge transport) and \# PHY-0646094. C.A.N. acknowledges support from the Netherlands Organization for Scientific Research (NWO) through a Rubicon grant and the Singapore National Research Foundation under 
NRF Award No. NRF-RF2010-03. M.M.T. was supported by a Mary-Fieser fellowship from Department of Chemistry, Harvard University and a postdoctoral fellowship from the NanoScience and Engineering Centre (NSEC) at Harvard University. 


\section{References}

${ }^{1}$ Aviram, A.; Ratner, M. A. Chem. Phys. Lett. 1974, 29, 277-283.

${ }^{2}$ Chabinyc, M. L.; Chen, X.; Holmlin, R. E.; Jacobs, H.; Skulason, H.; Frisbie, C. D.; Mujica, V.; Ratner, M. A.; Rampi, M. A.; Whitesides, G. M. J. Am. Chem. Soc. 2002, $124,11730-11736$.

${ }^{3}$ Kushmerick, J. G.; Whitaker, C. M.; Pollack, S. K.; Schull, T. L.; Shashidhar, R. Nanotechnology 2004, 15, S489-S493.

${ }^{4}$ Honciuc, A.; Jaiswal, A.; Gong, A.; Ashworth, K.; Spangler, C. W.; Peterson, I. R.; Dalton, L. R.; Metzger, R. M. J. Phys. Chem. B 2005, 109, 857-871.

${ }^{5}$ Lenfant, S.; Guerin, D.; Van, F. T.; Chevrot, C.; Palacin, S.; Bourgoin, J. P.; Bouloussa, O.; Rondelez, F.; Vuillaume, D. J. Phys. Chem. B 2006, 110, 13947- 13958.

${ }^{6}$ Metzger, R. M. Chem. Rev. 2003, 103, 3803-3834.

${ }^{7}$ McCreery, R. L. Chem. Mater. 2004, 16, 4477-4496.

${ }^{8}$ Troisi, A.; Ratner, M. A. J. Amer. Chem. Soc. 2002, 124, 14528-14529.

${ }^{9}$ Twardowski, M.; Nuzzo, R. G. Langmuir 2003, 19, 9781-9791.

${ }^{10}$ Zhou, C.; Deshpande, M. R.; Reed, M. A.; Jones, K., II; Tour, J. M. Appl. Phys. Lett. 1997, 71, 611-613.

${ }^{11}$ Waldeck, D. H.; Beratan, D. N. Science 1993, 261, 576-577.

${ }^{12}$ Ashwell, G. J.; Stokes, R. J. J. Mater. Chem. 2004, 14, 1228-1230.

${ }^{13}$ Weiss, E. A.; Kaufman, G. K.; Kriebel, J. K.; Li, Z.; Schalek, R.; Whitesides, G. M. Langmuir 2007, 23, 9686-9694.

${ }^{14}$ Weiss, E. A.; Chiechi, R. C.; Kaufman, G. K.; Kriebel, J. K.; Li, Z.; Duati, M.; Rampi, M. A.; Whitesides, G. M. J. Am. Chem. Soc. 2007, 129, 4336-4349.

${ }^{15}$ Hegner, M.; Wagner, P.; Semenza, G. Surf. Sci. 1993, 291, 39-46.

${ }^{16}$ Blackstock, J. J.; Li, Z.; Freeman, M. R.; Stewart, D. R. Surf. Sci. 2003, 546, 87-96.

${ }^{17}$ Regan, M. J.; Tostmann, H.; Pershan, P. S.; Magnussen, O. M.; DiMasi, E.; Ocko, B. M.; Deutsch, M. Phys. Rev. B 1997, 55, 10786-10790.

${ }^{18}$ Cademartiri, L.; Thuo, M. M.; Nijhuis, C. A.; Barber, J. R.; Sodhi, R. N. S.; Brodersen, P.; Kim, C.; Reus, W. F.; Chiechi, R. C.; Whitesides, G. M. J. Phys. Chem C. (submitted) 
${ }^{19}$ (a) M. Chelvayohan and C. H. B. Mee, J. Phys. C 1982, 15, 2305-2312. (b) R. C. Monreal, L. Guillemot, and V. A. Esaulov, J. Phys.: Condens. Matter 2003, 15, $1165-$ 1171. (c) K. Giesen, F. Hage, F. J. Himpsel, H. J. Riess, W. Steinmann, and N. V. Smith, Phys. Rev. B 1987, 35, 975-978.

${ }^{20}$ Barr, T. L.; Seal, S. J. Vac. Sci. Technol. A 1995, 13, 1239-1246.

${ }^{21}$ Thuo, M. M.; Reus, W. F.; Nijhuis, C. A.; Barber, J. R.; Kim, C.; Schulz, M. D.; Whitesides, G. M. J. Am. Chem. Soc. 2011, 133, 2962-2975.

${ }^{22}$ Nijhuis, C.A.; Reus, W.F.; Whitesides, G.M., J. Am. Chem. Soc., 2010, 132, 1838618401.

${ }^{23}$ Nijhuis, C. A.; Reus, W. F.; Whitesides, G. M. J. Am. Chem. Soc. 2009, 131, 1781417827.

${ }^{24}$ Nijhuis, C. A.; Reus, W. F.; Barber, J. R.; Dickey, M. D.; Whitesides, G. M. Nano Lett. 2010, 10, 3611-3619.

${ }^{25}$ Strukov, D. B.; Snider, G. S.; Stewart, D. R.; Williams, R. S. Nature 2008, 453, 80-83.

${ }^{26}$ Kittlesen, G. P.; White, H. S.; Wrighton, M. S. J. Am. Chem. Soc. 1985, 107, 73737380 .

${ }^{27}$ Ashwell, G. J.; Sambles, J. R.; Martin, A. S.; Parker, W. G.; Szablewski, M. J. Chem. Soc., Chem. Commun. 1990, 1374-1376.

${ }^{28}$ Chen, B.; Metzger, R. M. J. Phys. Chem. B 1999, 103, 4447-4451.

${ }^{29}$ Metzger, R. M. The Chemical Record 2004, 4, 291-304.

${ }^{30}$ Ashwell, G. J.; Tyrrell, W. D.; Whittam, A. J. J. Am. Chem. Soc. 2005, 126, 71027110 .

${ }^{31}$ Ashwell, G. J.; Mohib, A. J. Am. Chem. Soc. 2005, 127, 16238-16244.

32 Ashwell, G. J.; Urasinska, B.; Tyrrell, W. D. Phys. Chem. Chem. Phys. 2006, 8, 33143319.

${ }^{33}$ Kornilovitch, P. E.; Bratkovsky, A. M.; Williams, R. S. Phys. Rev. B 2002, 66, 165436/1-11.

${ }^{34}$ Larade, B.; Bratkovsky, A. M. Phys. Rev. B 2003, 68, 235305-.

${ }^{35}$ Liu, R.; Ke, S. H.; Yang, W.; Baranger, H. J. Chem. Phys. 2006, 124, 024718.

${ }^{36}$ Zhou, Y.; Zheng, X.; Xu, Y.; Zeng, Z. Y. J. Chem. Phys. 2006, 125, 244701. 
${ }^{37}$ Chang, S. C.; Li, Z.; Lau, C. N.; Larade, B.; Williams, R. S. Appl. Phys. Lett. 2003, 83, 3198.

${ }^{38}$ McCreery, R.; Dieringer, J.; Solak, A. O.; Snyder, B.; Nowak, A. M.; McGovern, W. R.; DuVall, S. J. Am. Chem. Soc. 2003, 125, 10748-10758.

${ }^{39}$ McCreery, R.; Dieringer, J.; Solak, A. O.; Snyder, B.; Nowak, A. M.; McGovern, W. R.; DuVall, S. J. Am. Chem. Soc. 2004, 126, 6200.

${ }^{40}$ Li, W. W.; Heinze, J.; Haehnel, W. J. Am. Chem. Soc. 2005, 127, 6140-6141.

${ }^{41}$ Chen, C.; Liu, Y-Z.; Shia, K-S.; Tseng, H-Y. Bioorg. Med. Chem. Lett. 2002, 12, 27292732 .

${ }^{42}$ Casella, G.; Berger, R. L. Statistical Inference; Duxbury Press: Belmont, California, 1990.

${ }^{43}$ M. Chelvayohan and C. H. B. Mee, J. Phys. C: solid state physics 1982, 15, $2305-$ 2312.

${ }^{44}$ R. C. Monreal, L. Guillemot, and V. A. Esaulov, J. Phys.: Condens. Matter 2003, 15, $1165-1171$.

${ }^{45}$ K. Giesen, F. Hage, F. J. Himpsel, H. J. Riess, W. Steinmann, and N. V. Smith, Phys. Rev. B 1987, 35, 975-978.

${ }^{46}$ Reus, W. F.; Nijhuis, C. A.; Barber, J. R.; Thuo, M. M.; Tricard, S.; Kim, C.; Whitesides, G. M. J. Phys. Chem. C. manuscript submitted.

${ }^{47}$ Galwey, N. W. Genetic Epidemiology 2009, 33, 559.

${ }^{48}$ The terms "work function" and "Fermi energy" are similar, and are often used synonymously. Technically, the work function is the amount of energy required to remove an (average) electron from a material to vacuum, while the Fermi energy is the energy (with respect to vacuum) at which $50 \%$ of the electronic states in the material are occupied. Although the two concepts are subtly different, their differences do not affect the present discussion.

${ }^{49}$ Brinkman, W. F.; Dynes, R. C.; Rowell, J. M. J. Appl. Phys. 1970, 41, 1915-1921.

${ }^{50}$ Krishnan, S.; Stefanakos, E.; Bhansali, S. Thin Solid Films 2008, 516, 2244-2250.

${ }^{51}$ Muller-Meskamp, L.; Karthauser, S.; Zandvliet, H. J. W.; Homberger, M.; Simon, U.; Waser, R. Small, 2009, 5, 496-502.

${ }^{52}$ Spicer, W. E.; Lindau, I.; Skeath, P.; Su, C. Y.; Chye, P. Phys. Rev. Lett. 1980, 44, 420-423. 
${ }^{53}$ Lorenz, M. R.; Woods, J. F.; Gambino, R. J. J. Phys. Chem. Solids 1967, 28, 403-404.

${ }^{54}$ Ueda, N.; Hosono, H.; Waseda, R.; Kawazoe, H. Appl. Phys. Lett. 1997, 70, 35613563 .

${ }^{55}$ Wimbush, K. S.; Reus, W. F.; Wiel, W. G. V.d.; Reinhoudt D. N.; Whitesides, G. M.; Nijhuis, C. A.; Velders, A. H. Angew. Chem. Int. Ed. 2010, 122, 10374-10378. 